\title{
Observational evaluation of outdoor cooling potential of air-source heat pump water heaters
}

\author{
Kazuki Yamaguchi ${ }^{1}$ (1) $\cdot$ Tomohiko Ihara $^{2} \cdot$ Yukihiro Kikegawa $^{3}$
}

Received: 13 August 2020 / Accepted: 26 May 2021 / Published online: 10 June 2021

(c) The Author(s) 2021

\begin{abstract}
Heat pump water heaters are highly efficient hot water supply systems that effectively utilize the heat of outdoor air via heat pump technology. Many studies have been conducted to optimize the design and operation of heat pump water heaters from the perspective of climate change mitigation. Air-source heat pump water heaters, which absorb heat from the outdoor air and emit cold exhaust, can also be expected to alleviate the urban heat island effect; however, this has not been studied extensively. To estimate the impact of cold exhaust on building-scale climate, we conducted a multipoint measurement of the outdoor thermal environment around a low-rise apartment building equipped with air-source heat pump water heaters, in both summer and winter. Observations showed a substantial cooling effect that decreased air temperatures by $1{ }^{\circ} \mathrm{C}$ within the site boundary on summer nights when multiple heat pump water heaters operated concurrently. The analysis revealed that the sensitivity of the ambient temperatures to cold exhaust depends strongly on local atmospheric conditions. The most influential factor was the wind direction: the sensitivity increased significantly when the exhaust outlet location was at the lee side of the building. Naturally, the wind speed also affected the sensitivity, which tended to be higher when the wind speed was lower. The convective stability near the ground surface, however, showed no significant influence over the sensitivity.
\end{abstract}

Keywords Air-source heat pump water heater $\cdot$ Cold exhaust $\cdot$ Urban heat island $\cdot$ Building-scale climate $\cdot$ Observation

\section{Introduction}

According to IPCC AR4 WG2 (2007), it is now clear that mitigation alone cannot prevent the effects of climate change. Thus, the international community is promoting both mitigation and adaptation as ways to combat climate change. In particular, urban areas, which consume a large amount of energy, suffer from the combined impact of global warming and the urban heat island (UHI) effect. A balanced combination of measures consisting of mitigation and adaptation is required to tackle this issue.

Kazuki Yamaguchi

yamaguchi.ka@tepco.co.jp

1 TEPCO Research Institute, Tokyo Electric Power Company Holdings, Inc, 4-1 Egasaki-cho, Tsurumi-ku, Yokohama, Kanagawa 230-8510, Japan

2 Graduate School of Frontier Sciences, The University of Tokyo, 5-1-5 Kashiwanoha, Kashiwa, Chiba 277-0882, Japan

3 School of Science and Engineering, Meisei University, 2-1-1 Hodokubo, Hino, Tokyo 191-8506, Japan
Water heating accounts for a large percentage of total energy consumption in the domestic sector, estimated at $14 \%$ in the USA (IEA 2018), 16.8\% in the UK (BEIS 2019), and 29.1\% in Japan (ANRE 2019); it is also a major source of $\mathrm{CO}_{2}$ emissions. The air-source heat pump water heater (ASHPWH) system is a highly efficient hot water supply device that employs heat pump technology to effectively utilize the heat of outdoor air. This is a technology expected to contribute to the mitigation of climate change by reducing $\mathrm{CO}_{2}$ emissions.

The performance of ASHPWH systems is affected by characteristics of the external environment, such as outdoor air temperature and supply water temperature. Morrison et al. (2004) showed that according to experiment-based seasonal performance assessments, air temperature had a greater impact than water temperature. Yokoyama et al. (2007) noted that, according to numerical simulations, outdoor air temperatures have a significant impact on system efficiency and energy consumption. Guo et al. (2011) conducted model simulations to improve design and operational optimization in terms of the thermal and economic performance. Their results showed that the optimal starting time 
is determined by the difference in the unit cost of electricity between day and night, but the optimal setting water temperature is determined according to the seasonal change in the outdoor air temperature.

ASHPWH systems are less suitable for cold climates because low outdoor temperatures lead to reduced efficiency (Singh et al. 2010); however, field experiments in the northeastern and northwestern parts of the USA have shown that the system coefficient of performance (COP) reaches 1.5 - 2.6 (Shapiro and Puttagunta 2016; Ecotope and NEEA 2015). This means a $40-65 \%$ reduction in secondary energy consumption compared to a conventional electric water heater or a gas water heater with thermal efficiencies of around 0.9 . Further improving the performance of air-source heat pumps (for space or water heating) at low temperatures has been a major focus in recent years, and numerous research studies have been carried out (e.g., TelloOquendo et al. 2019; Kim et al. 2019; Wei et al. 2020a, b).

One problem with heat pump water heaters is that hydrofluorocarbons (HFCs), which are used as refrigerants, have an extremely high global warming potential (GWP). Therefore, considering HFC leakage, it has been calculated that the lack of adequate performance in cold climates can lead heat pump water heaters to have the same environmental impact, in terms of greenhouse gas emissions, as gas water heaters (Johnson 2011). Thus, $\mathrm{CO}_{2}$, which has a low GWP and performs excellently as a refrigerant, has been attracting attention as a possible replacement for HFCs. Nekså et al. (1998) showed that a prototype heat pump water heater using $\mathrm{CO}_{2}$ as a refrigerant yielded an annual average $\mathrm{COP}$ of around 4, even under climatic conditions in Oslo. In addition, an investigation by Cecchinato et al. (2005) using a simulation showed that the $\mathrm{COP}$ of $\mathrm{CO}_{2}$-ASHPWH systems could reach between 4 and 5 in winter (with an outdoor air temperature of $10^{\circ} \mathrm{C}$ ) and between 7 and 9 in summer (with an outdoor air temperature of $30^{\circ} \mathrm{C}$ ).

There have been many studies focused on the dependency of COP, and other associated parameters, on outdoor air temperature; this is to optimize the design and operation of ASHPWH systems. This is done mainly from the viewpoint of climate change mitigation. However, the impact of the operation of ASHPWHs on outdoor air temperatures has not attracted as much attention. In theory, ASHPWHs are able to contribute to outdoor air cooling by reducing anthropogenic heat emissions, as explained below:

(1) The amount of energy consumed by a hot water system is equal to the final amount of heat emission. To obtain a heat output of 100 units in the form of hot water, a conventional gas-fired or electric water heater with a thermal efficiency of 0.8 requires 125 units of combustion energy, and ultimately emits a total of 125 units of heat (100 units as hot water and 25 units as exhaust heat). In contrast, an ASHPWH with a COP of 4 requires 25 units of electric energy and absorbs 75 units of external thermal energy from outdoor air; this results in a heat output of 100 units. However, because 75 units are emitted as cold exhaust, the amount of absorption takes a negative value, resulting in a net emission of 25 units (100 units as hot water and -75 units as cold exhaust). Thus, ASHPWHs can greatly reduce heat emission compared to conventional gas/ electric water heaters.

(2) Cold exhaust from the outdoor units of ASHPWHs does not diffuse easily since it is on average several degrees Celsius cooler than the ambient temperature, and it therefore tends to sink. Thus, its effect on the air temperature at ground level can be significantly greater than that from hot exhaust. In addition, the cold exhaust occurs at night when the atmosphere is more stable and has an enhanced cooling effect compared to that observed during the daytime. Therefore, even if the net heat emission is positive, the cooling effect of the cold exhaust greatly exceeds the effect of the hot exhaust.

(3) While a significant portion of the heat from waste water would be conveyed far from the residential area in the city, cold exhaust is emitted on site. If we assume the residential area as the system boundary, it can be considered that ASHPWHs recover excess heat within the system and eventually dump the recovered heat out of the system.

A pronounced increase in nighttime temperatures compared to the daytime equivalent is a common phenomenon in global warming (Karl et al. 1993; Alexander et al. 2006; Davy et al. 2016) and UHI (Clarke 1972; Oke 1982; Wilby 2003); in cities, nighttime temperatures are found to be rising faster than daytime temperatures. For example, the daily maximum and minimum temperatures in Tokyo have increased at 1.3 and $2.9^{\circ} \mathrm{C}$ per 100 years, respectively (JMA 2020).

The various negative impacts of nighttime UHIs on the health of urban residents have become a serious social problem. Heat-related mortality is closely related to nighttime outdoor temperatures (Clarke 1972; McGeehin and Mirabelli 2001; Yang et al. 2013; Murage et al. 2017). The urban mortality rate during heatwaves was much higher than suburban and rural mortality rates. This is attributable to the higher thermal stress that occurs within cities, and in particular, the lack of adequate relief from thermal stress at night (Clarke 1972). Although sleep disorders from high temperatures are minor non-fatal health problems, they have a high morbidity rate and thus, affect a larger population (Ihara et al. 2015). A significant correlation between outdoor temperature at night and the incidence of sleep disorders has been confirmed in many studies across different cities (Nastos and Matzarakis 
2008; Narumi et al. 2016; van Loenhout et al. 2016; Obradovich et al. 2017).

Nighttime UHI has also been associated with an apparent increase in the incidence of indoor heat stroke at night. Heat stroke tends to be more severe at night as people are unaware of the onset of early symptoms during sleep. In 2019, approximately half the heat stroke deaths across the 23 wards in Tokyo occurred at night; $90.3 \%$ occurred indoors, and $82.2 \%$ were people aged 65 and older. Furthermore, in $85.2 \%$ of deaths that occurred indoors, air conditioning was not being utilized (Bureau of Social Welfare and Public Health 2019). Miyake et al. (2010) investigated the characteristics of heat stroke patients in Japan and found that for indoor incidents, the proportion of air conditioning use was low among the elderly. Previous studies have shown that approximately $26-60 \%$ of elderly people do not use air conditioning at bedtime (Shibata et al. 2010; Kayaba et al. 2013; Tanaka and Umeda 2015), as they prefer opening windows to allow for natural ventilation (Kayaba et al. 2013).

In general, the use of air conditioners is able to reduce health risks due to the indoor thermal environment (Bouchama et al. 2007; Karkour et al. 2021). Regardless, nighttime health hazards have become a serious issue, even in urban residential areas of Tokyo where air conditioning usage is widespread. Many residences in the mega-cities of tropical developing countries have low air conditioning penetration rates (IEA 2018), and there are concerns that increased nighttime temperatures associated with progressive urbanization will increase the prevalence of serious health problems. Traditionally, in tropical regions such as South and Southeast Asia, natural ventilation is an effective passive solution to improve indoor thermal comfort by minimizing the effects of hot and humid air (Kubota et al. 2018; Enteria et al. 2020). In the central regions of Japan which experiences large temperature fluctuations from season to season, natural ventilation has traditionally been emphasized in housing designs as opposed to than airtightness, and summer thermal comfort is prioritized (Yoshino et al. 2007; Kobayashi 2018).

Many studies have evaluated the cooling potential of various ventilation techniques, finding that nighttime ventilation (i.e., the introduction of outdoor air at lower temperatures), is more effective than daytime ventilation in terms of improving the indoor thermal environment (Kubota et al. 2009; Michael et al. 2017; Oropeza-Perez and Østergaard 2018; Suárez et al. 2018; Tuck et al. 2019). However, as indoor temperatures are highly correlated with outdoor temperatures (Tuck et al. 2019), the efficiency of nighttime ventilation is severely compromised if there is a considerable rise in nighttime outdoor temperatures.

These findings suggest that the elderly in Japan refrain from using air conditioning at bedtime due to traditional values favoring natural ventilation. Additionally, the rapid deterioration of the nighttime thermal environment undermines its effectiveness in improving the indoor thermal environment, ultimately leading to an increase in health hazards. The widespread use of air conditioning alone is insufficient as an adaptive measure to address these health problems. The significant relationship between nighttime outdoor temperatures and health hazards suggests that measures to reduce nighttime outdoor temperatures may be effective.

Increasing the albedo of city surfaces or installing vegetated green surfaces are promising measures for alleviating the UHI, and many studies have been conducted to evaluate their effects (e.g., Rosenfeld et al. 1995; Savio et al. 2006; Synnefa et al. 2008; Chen et al. 2009; Zhou and Shepherd 2010; Ng et al. 2012). However, although these measures are effective in lowering daytime temperatures, their effects on nighttime temperatures are limited. Santamouris (2012) reviewed several simulation studies and showed that when the albedo of city surfaces is globally increased, the expected mean decrease in the average ambient temperature is approximately $0.3^{\circ} \mathrm{C}$ per 0.1 rise in albedo, and the corresponding average decrease of the peak ambient temperature is approximately $0.9^{\circ} \mathrm{C}$. Similarly, the average and peak values for cool roofs were $0.2{ }^{\circ} \mathrm{C}$ and $0.41{ }^{\circ} \mathrm{C}$ (per 0.1 rise in albedo), respectively; for green roofs, the average and peak values range from 0 (negligible) $-0.55^{\circ} \mathrm{C}$ and $0-0.86{ }^{\circ} \mathrm{C}$, respectively. Because the peak values appear during the day, the corresponding values at night are smaller than the average values, suggesting the difficulty of lowering the outdoor temperature at night.

Given this context, there is a need to verify the effectiveness of the ASHPWH as a measure of nighttime UHI. The use of ASHPWHs to lower nighttime outdoor temperatures in the vicinity of residential buildings and improve the indoor thermal environment by introducing cooled air through ventilation is a potential adaptation measure for climate change. The design and operation of ASHPWHs may be optimized for mitigative and adaptative measures in response to climate change; however, few studies have evaluated ASHPWHs as an adaptation measure.

To maximize the outdoor cooling potential of the ASH$\mathrm{PWH}$, it is essential to understand the characteristics of anthropogenic-induced cold heat. Anthropogenic heat, artificial ground surfaces, and urban morphology have long been considered and studied as the three primary factors causing the UHI. It is known that the impact of these factors on city temperatures varies with time and season, and that anthropogenic heat contributes greatly to the rise of temperatures at night and in winter (Atwater 1972; Ichinose et al. 1999; Kusaka and Kimura 2004; Fan and Sailor 2005; Ryu and Baik 2012). Kimura and Takahashi (1991) conducted an experiment using a regional climate model and found that anthropogenic heat has contributed to an increase in surface temperatures in the Tokyo metropolitan area of $1{ }^{\circ} \mathrm{C}$ 
during the day and $2-3{ }^{\circ} \mathrm{C}$ at night. Ohashi et al. (2007) used observations and simulations to compare the outdoor air temperatures during weekdays and holidays in office districts in central Tokyo and showed that temperatures during the summer were $1-2{ }^{\circ} \mathrm{C}$ higher due to heat exhaust from air conditioners. As the impacts of anthropogenic heat on urban temperatures also depend on urban morphology, studies on this have also been conducted using computational fluid dynamics (CFD) simulation (e.g., Adelia et al. 2019).

However, these studies are aimed at hot exhausts, which have higher temperatures than ambient air. There are only a few previous studies on the effects of "cold exhausts," from ASHPWH. The temperature impact of the assumed widespread use of ASHPWH has been evaluated using numerical simulations from the mesoscale to the city-block scale; it is shown that a decrease of approximately $0.5-0.6{ }^{\circ} \mathrm{C}$ occurs at night in summer (Tamura et al. 2003; Yamaguchi et al. 2016) and the cooling potential is higher in dense residential areas (Takebayashi et al. 2009). However, this research is still in the preliminary stages, whereby observational measurements have not yet been conducted to verify the simulation results. Although these studies focus on the impact at various scales, it is difficult to verify the impact of cold exhaust at the broad-area scale in the current situation where ASHPWH is not yet widespread. Considering prospects for the spread of the ASHPWH in the future, it is meaningful to examine its outdoor cooling potential using building scale observations. This study recorded measurements of the thermal environment near a low-rise residential apartment building equipped with ASHPWHs.

The cooling effect can be concluded directly in accordance with the law of conservation of energy. As the ASHPWH absorbs heat from the ambient air around the target building, temperature reductions in the ambient air are likely. The research has the following two main objectives:

(1) To quantitatively measure the thermal environment at the building scale under actual uncontrolled ASHPWH operating conditions.

(2) To qualitatively analyze and identify meteorological factors that influence the effect of temperature reduction to achieve an approximate understand how the cooling effect depends on local atmospheric conditions, such as wind direction, wind speed, and thermal convection.

In terms of (1), a temperature drop of approximately $1{ }^{\circ} \mathrm{C}$, which is comparable to the maximum daytime peak effect of cool and green roofs (Santamouris, 2012), would justify the implementation of further detailed studies and the consideration of ASHPWHs as a promising countermeasure to nighttime UHIs in summer. Regarding (2), the measurements conducted on a real house in this study have many constraints and a large degree of uncertainty. To conduct a quantitative analysis of the relationship between the amount of exhaust heat, local atmospheric conditions, and temperature reduction, experiments in a controlled environment are necessary. Such a quantitative analysis will be the focus of subsequent studies after the objectives of this study are achieved.

\section{Methods and conditions}

\subsection{Outline of the measurement}

We selected a low-rise apartment building in Shinjuku Ward, Tokyo, as our target building (Fig. 1). It is built of reinforced concrete with three floors aboveground $(10.0 \mathrm{~m}$ height). The site has an area of $910 \mathrm{~m}^{2}(40.9 \mathrm{~m} \times 22.3 \mathrm{~m})$, of which the building occupies $230 \mathrm{~m}^{2}(27.5 \mathrm{~m} \times 8.4 \mathrm{~m})$, and the total floor space is $630 \mathrm{~m}^{2}$. It accommodates 16 households, with an average occupied area of about $30 \mathrm{~m}^{2}$ per household; 12 of these are single-occupancy, while the other 4 are double-occupancy. The occupants were not informed about the purpose of the observation to avoid influencing their hot water usage. $\mathrm{A} \mathrm{CO}_{2}-\mathrm{ASHPWH}$ (Corona, CHP-452) is installed in each apartment. A total of 12 outdoor units were placed in four vertical rows (columns \#1 -4) by three horizontal rows (top, middle, and
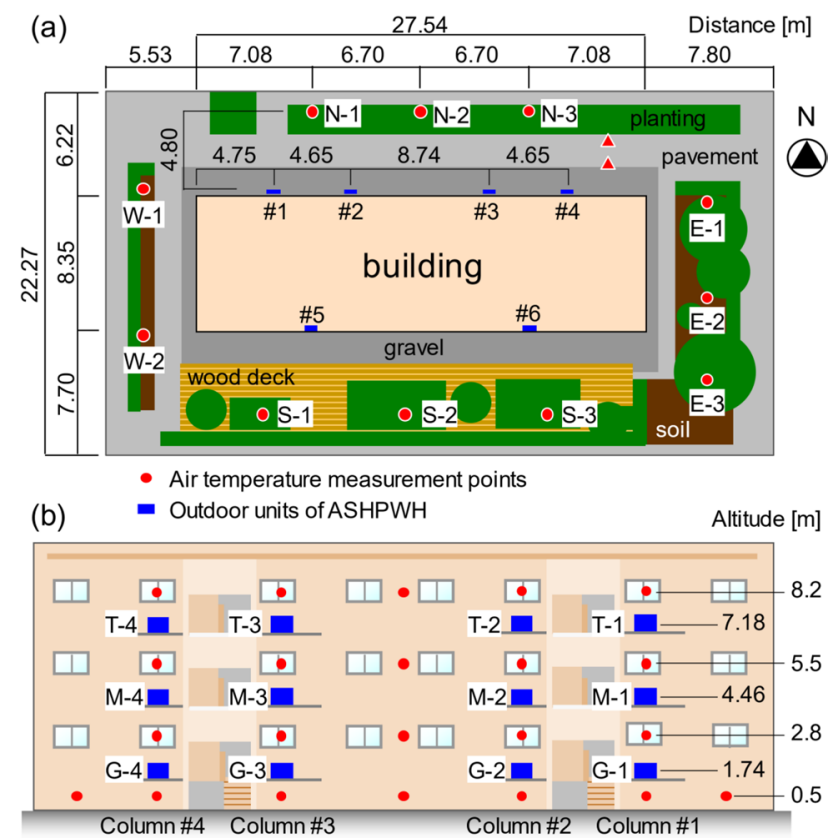

Fig. 1 a Location of columns of outdoor ASHPWH units and air temperature measurement points $1.5 \mathrm{~m}$ above ground at the site (top view). The red triangles indicate the measurement points for ground surface temperatures. b Location of outdoor ASHPWH units and air temperature measurement points along the northern wall of the building (front view). The measurement points only were set during the summer observation period 
ground floors) on the northern side of the building; the other four units were placed in two columns (\#5 and \#6) by two rows (top and middle floors) on the southern side. The site is surrounded by $2-\mathrm{m}$ high fences. The northern and southern boundaries have blindfolded fences with no openings, whereas the eastern and western boundaries have mesh fences with an opening ratio of approximately $90 \%$.

The observation periods were August 20-September 10, 2008 for summer and February 15-25, 2011 for winter. To measure the temperature of the outdoor air, thermistor thermometers (T\&D, RTR-52) fitted with solar shields were used. To capture the horizontal distribution of temperatures at a height of $1.5 \mathrm{~m}$, three measurement points were set on the eastern, southern, and northern sides of the site, and two points were set on the western side (Fig. 1a). In particular, the three measurement points on the northern side $(\mathrm{N}-1, \mathrm{~N}-2$, and $\mathrm{N}-3)$ were located at the midpoints of the adjacent vertical rows of exhaust outlets and as far from the outlets as possible to avoid the direct impact of cold exhaust before it diffuses. In addition, to capture the vertical structure of temperature, 7 measurement points were set at $0.5 \mathrm{~m}$ and 5 points were set at heights of $2.8 \mathrm{~m}$, $5.5 \mathrm{~m}$, and $8.2 \mathrm{~m}$, each positioned $0.3 \mathrm{~m}$ from the northside wall (Fig. 1b) during the summer observation period. Ground surface temperatures $\left(T_{g}\right)$ were measured at two points on the concrete pavement in the northern side of the site (Fig. 1a) using type-T thermocouple wires (Onset, TCW100-T), and the averaged values are used for the analysis. General weather conditions including air temperature $\left(T_{a}\right)$, wind speed, and wind direction were measured by a weather station (Davis, Vantage Pro2) installed $1.5 \mathrm{~m}$ from the surface of the roof, i.e., $11.5 \mathrm{~m}$ above the ground. The data measurement interval for the thermistor thermometer was set to $30 \mathrm{~s}$, the thermocouple was set to $1 \mathrm{~min}$, the weather station was set to $10 \mathrm{~min}$, and the average value over 10 min was used while analyzing the results. Each thermistor thermometer was calibrated using an Assmann ventilated psychrometer (Sato Keiryoki Mfg., SK-RHG-S), and the measured values were corrected using the relevant calibration formula.

Since we conducted the investigation in an occupied house, not an experimental location, the need for privacy for the occupants meant there were several limitations on taking measurements. Since only a few instruments could be placed discreetly within the site, detailed airflow data around the building could not be obtained. A further limitation stems from the nature of ambient air. If it was trapped in a certain area, it could act as a control so that we could determine the exact temperature drop. However, ambient air normally flows in many different directions, which made it difficult to measure the exact drop in temperature. In addition, energy-related data such as usage and schedules were not directly available for this study.

\subsection{Cold exhaust profile}

In order to evaluate the impact of the exhaust heat on outdoor air temperature, it is essential to know when and how much it is emitted. The ASHPWH is a thermal storage system that always operates at a rated load at a set time, regardless of the hot water consumption schedule. In order to minimize heat loss from the storage tank, and to simultaneously take advantage of the cheaper electricity rates offered at night, the system is usually pre-programmed to run from late night to early morning. Its operating time and the quantity of cold exhaust vary by season. The total amount of exhaust heat $H_{n}(\mathrm{~kW})$ from multiple water heater units can be estimated based on the heating capacity $Q$ (kW/unit), energy consumption $E$ (kW/unit), and number of operating units $n$ (units) using the following equation:

$H_{n}=(E-Q) n$.

In the case of the ASHPWH (with larger $Q$ than $E$ ), $H_{n}$ has a negative value indicating the amount of heat energy absorbed from outdoor air. Because the actual heating capacity and energy consumption could not be measured in this study, the rated values specified by the manufacturer were used to set $Q$ at 4.5 throughout the year and to estimate $E$ as a function of outdoor temperature (Eq. (4) in Appendix 1). The air temperature $T_{a}$ measured on the rooftop (described in the next section) was used as the outdoor temperature. As the air temperature near outdoor units decreases nonuniformly due to cold exhaust, in theory, the intake air temperature of each unit should be utilized. However, the results of the CFD evaluation show that consideration of the spatial variability of the intake temperature had no significant effect on the estimation of $H_{n}$ (Appendix 2). The value of $n$ was determined based on records of thermistor thermometers installed approximately $5 \mathrm{~cm}$ away from the front of the exhaust outlets of the outdoor units. Because the temperature of the cold exhaust was approximately $7^{\circ} \mathrm{C}$ below the ambient air temperature, the on/off status of each unit could be clearly determined. Of the 16 units on the site, the 12 units on the northern side of the building were targeted for monitoring, whereas the four units on the southern side were placed in private areas of the estate and not monitored in this study.

The results of the monitoring revealed that each unit operates at approximately the same time for each season (Fig. 2). Overall, the units primarily ran from 4:00 to 6:30 a.m. in the summer and from 1:30 to 6:30 a.m. in the winter. The winter duration is approximately two times longer than the summer duration, primarily because the input water temperature is lower in winter, requiring more energy to heat the water to the same temperature. Because each unit was operated on a pre-programmed schedule, the observed day-to-day 


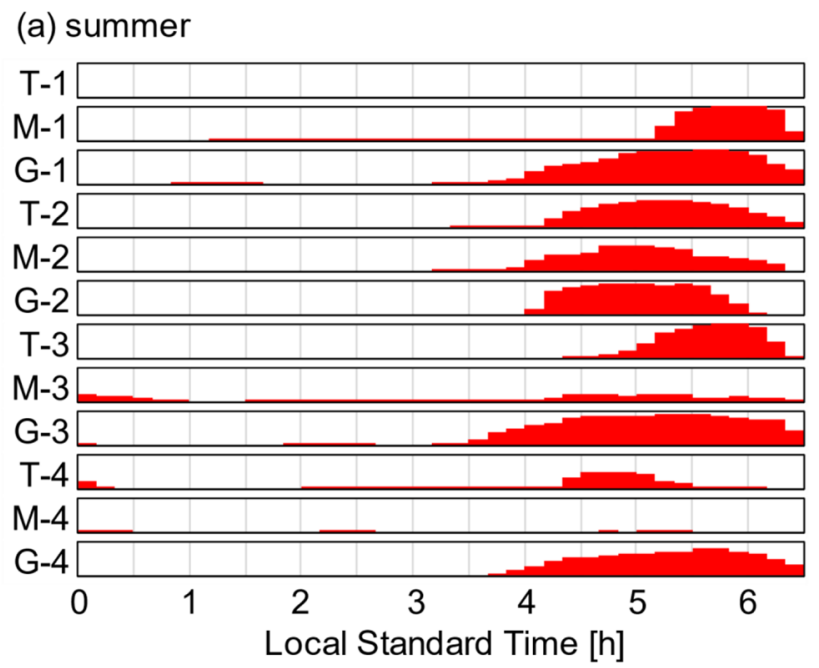

(b) winter

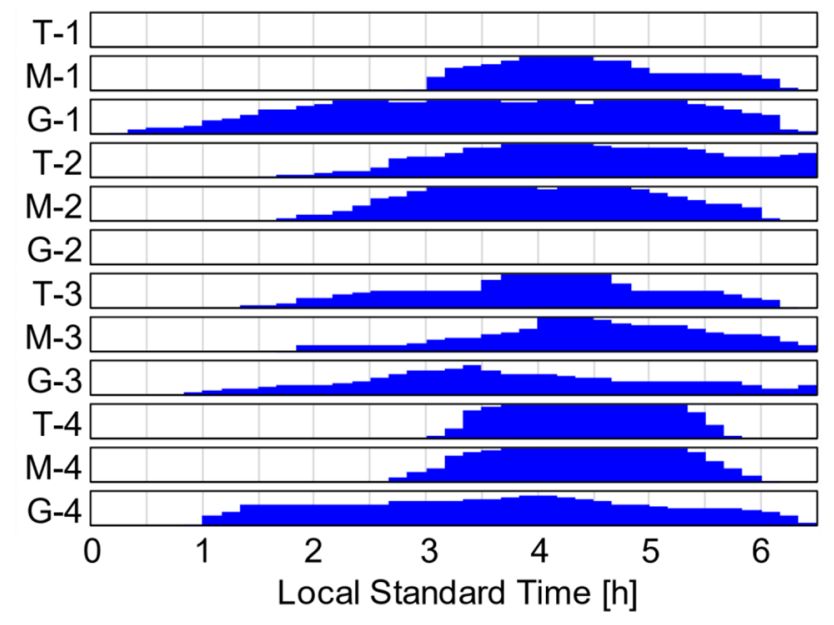

Fig. 2 Average operating rate of each ASHPWH unit on the northern side of the building for each observation period: a summer and b winter. The vertical axis of each panel ranges from 0 to $100 \%$. The time interval is $10 \mathrm{~min}$

variations in the number of active units were small. The average number of operating units $(n)$ peaked at 7.1 at 5:30 a.m. in the summer and at 9.4 at 4:10 a.m. in the winter. Units T-1, M-3, and M-4 in the summer and T-1 and G-2 in the winter either operated infrequently or were out of operation. The large number of single-occupancy apartments in the target building likely caused a lower demand for hot water than that of a standard household. Figure 3 shows the estimated average total amount of $H_{n}$ over time during each observation period. $H_{n}$ was nearly proportional to $n$-despite also depending on the outdoor temperature-with a peak value of -24.2 at 5:30 a.m. in the summer and -30.4 at 4:10 a.m. in the winter. The average daily integrated values of $H_{n}$ for summer and winter reach -123.9 and $-242.4 \mathrm{~kJ}$, respectively. If the total amount of the cold exhaust stayed in the space within a $10-\mathrm{m}$ height of the site $\left(6802 \mathrm{~m}^{3}\right.$ excluding

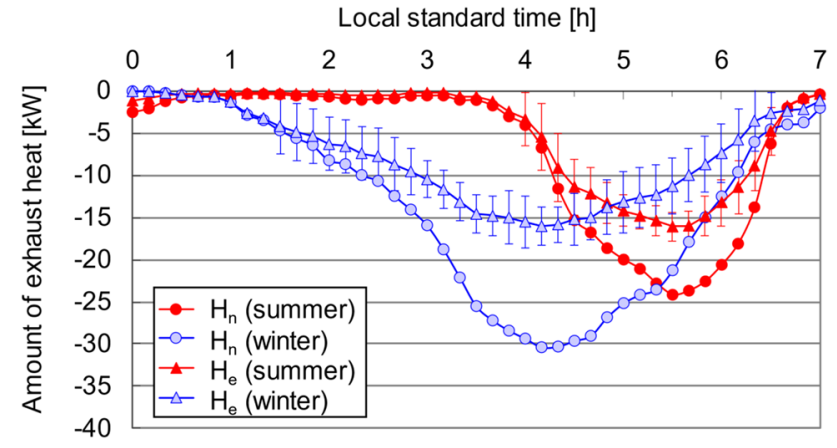

Fig. 3 Time series of estimated average total amount of cold exhaust $H_{n}$ and effective amount of cold exhaust $H_{e}$ (with standard deviation error bars) during each summer and winter observation period. Negative values indicate the amount of heat energy absorbed from outdoor air

the volume of the building), it could cause temperature drops of 15.3 and $28.2^{\circ} \mathrm{C}$ in summer (when the outdoor temperature is $25^{\circ} \mathrm{C}$ ) and winter (when the outdoor temperature is $7{ }^{\circ} \mathrm{C}$ ), respectively. In practice, under calm conditions, the cold exhaust assumedly sinks downward and spreads to more gently cool a wider area closer to the ground.

\subsection{Weather overview}

The air temperatures measured at the rooftop $\left(T_{a}\right)$ closely matched those of the Tokyo Meteorological Observatory, located approximately $4 \mathrm{~km}$ to the east. The similarities remained consistent throughout the entire period. The daily minimum of $T_{a}$ during the summer observation period ranged from 19.4 to $26.1{ }^{\circ} \mathrm{C}$, with an average of $23.1^{\circ} \mathrm{C}$, whereas that during the winter ranged from 0.7 to $7.9^{\circ} \mathrm{C}$, with an average of $4.6{ }^{\circ} \mathrm{C}$. Throughout the observation period for the summer of 2008 , the weather was relatively cool and only four tropical nights (nights with a minimum temperature of $25^{\circ} \mathrm{C}$ or higher) occurred; this observation can be attributed to the unstable atmosphere caused by low pressure and weather fronts in late August.

In this study, we grouped wind directions into two main directions: north (from WNW to ENE) and south (from ESE to WSW). Observations of the wind direction distribution showed that northerly winds were dominant when the ASHPWHs were in operation. During the summer observation period, northerly and southerly winds were observed in $82.7 \%$ and $15.5 \%$ of the operating hours (4:00-6:30 a.m.), respectively. During winter, northerly winds were observed in $90.6 \%$ of the operating hours (1:30-6:30 a.m.), whereas southerly winds were observed in only $3.5 \%$ of the operating hours; there were no days when the mean wind direction during the operating hours was southerly. When the wind speed, air temperature $\left(T_{a}\right)$, and ground surface temperature $\left(T_{g}\right)$ are averaged by main 
wind direction for each observation period (Table 1), the following trends were observed. During the summer observation period, compared to the northerly wind days, the southerly wind days were much calmer and hotter by about $3{ }^{\circ} \mathrm{C}$. The convective stability near the ground surface can be roughly estimated based on the difference between $T_{a}$ and $T_{g}$. It was in a nearly neutral state on the southerly wind days $\left(T_{g}-T_{a}=0.0^{\circ} \mathrm{C}\right)$, while it was unstable on the northerly wind days $\left(T_{g}-T_{a}=2.9^{\circ} \mathrm{C}\right)$. These observations confirm that the UHI is more intense under calm and stable atmospheric conditions. On the northerly wind days in winter, the average wind speed was at par with that of northerly wind days in summer; however, it was rather stable $\left(T_{g}-T_{a}=-1.7^{\circ} \mathrm{C}\right)$ in terms of convective state near the ground surface.

\subsection{Quantification of the cooling effects}

While quantifying the temperature decrease due to cold exhaust from ASHPWHs, the measured air temperature on the rooftop $\left(T_{a}\right)$ was set as the baseline on the assumption that it is not affected by the cold exhaust. Biases were removed for the air temperature at each measurement point so that the average value during the period when the ASHPWHs did not operate (0:00 - 3:00 a.m. for summer and 23:00 $\mathrm{pm}-0: 00 \mathrm{a} . \mathrm{m}$. for winter) was equal to the rooftop air temperature. The deviation from the rooftop air temperature $(\Delta T)$ at each measurement time was regarded as being influenced by the cold exhaust.

However, since the temperature measured on the rooftop might be affected by the cold exhaust to some extent, the value of $\Delta T$ obtained by this method tended to be underestimated. On the other hand, since the rooftop air temperature rises the fastest after sunrise, the $\Delta T$ at each measurement point in this case becomes excessive. The sunrise time during each observation period was around 5:10 a.m. for summer and 6:20 a.m. for winter. Here, to avoid overestimation, we mainly discuss the evaluation value $\Delta T$ before 5:00 a.m. It should also be noted that as $\Delta T$ typically takes on a negative value, when evaluating the magnitude of its value, terms such as great, large, or small indicate the magnitude of the absolute value.

\subsection{Minimizing uncertainties}

This study focuses on building-scale phenomena in order to improve the indoor thermal environment by introducing cool air near buildings through ventilation. To best utilize the cooling potential of cold exhaust, it is critical to understand factors that affect the temperature sensitivity to the amount of cold exhaust $\left(\Delta T / H_{n}\right)$. However, the results from this study contain various uncertainties, as it was conducted under highly constrained and uncontrolled conditions. To minimize the effects of these uncertainties and obtain robust results attributable only to the observed facts, it was important to carefully consider the evaluation indices.

First, as the wind speed observation point was only on the rooftop, local airflow near the ground could not be captured. The observed values of $\Delta T$ were averaged as appropriate, to minimize the influence of unobserved irregular airflow. The effects of temporal and spatial irregularities were reduced by seasonal and regional averaging, respectively.

Additionally, the cold exhaust from the four units on the southern side of the building was not monitored; this introduces major uncertainty that creates challenges for evaluation. To minimize the influence of cold exhaust from the south side, only three measurement points on the northern side (N-1, N-2, and N-3) were considered for temperature sensitivity evaluation. As the north side is where the largest number of emission sources are located, a focus on this side is reasonable in terms of utilizing the cold through ventilation.

The horizontal and vertical distributions of multiple exhaust outlets were another primary factor that made the evaluation of temperature sensitivity $\left(\Delta T / H_{n}\right)$ difficult in this study. In general, higher exhaust outlet locations closer to the boundary in the horizontal direction lead to greater advection-diffusion from the target area and a smaller temperature effect within the area. For the placement of outdoor units in this study in particular, a significant proportion of cold exhaust from higher floors was found to escape over the fence without affecting the observed air temperature. This means that $\Delta T / H_{n}$ differs at a specific measurement point depending on the location of the emission. As the operation of each unit was not controlled in its entirety, the multiple emission locations vary irregularly over time,
Table 1 Overview of weather by wind direction during the operation times of ASHPWH. Wind directions are grouped into two main directions: north (from WNW to ENE) and south (from ESE to WSW)

\begin{tabular}{llllll}
\hline Observation period & $\begin{array}{l}\text { Main wind } \\
\text { direction }\end{array}$ & $\begin{array}{l}\text { Average } \\
\text { wind speed }\end{array}$ & $\begin{array}{l}\text { Average air } \\
\text { temperature }\end{array}$ & $\begin{array}{l}\text { Average ground } \\
\text { surface temperature }\end{array}$ & $\begin{array}{l}\text { Total \# of } \\
\text { observed } \\
\text { days }\end{array}$ \\
\hline Summer (4:00-6:30 a.m.) & North & $1.0 \mathrm{~m} / \mathrm{s}$ & $22.6{ }^{\circ} \mathrm{C}$ & $23.5{ }^{\circ} \mathrm{C}$ & 18 \\
& South & $0.4 \mathrm{~m} / \mathrm{s}$ & $25.4{ }^{\circ} \mathrm{C}$ & $25.4{ }^{\circ} \mathrm{C}$ & 4 \\
Winter (1:30-6:30 a.m.) & North & $1.2 \mathrm{~m} / \mathrm{s}$ & $5.4{ }^{\circ} \mathrm{C}$ & $3.7{ }^{\circ} \mathrm{C}$ & 11 \\
& South & - & - & - & 0 \\
\hline
\end{tabular}


making it difficult to evaluate $\Delta T / H_{n}$ under constant conditions. To qualitatively analyze the effect of meteorological factors on $\Delta T / H_{n}$, the effect of the emission location should be excluded from the evaluation index. The CFD evaluation results show that under calm conditions, the cold exhaust from the middle and top floors registered $44 \%$ and $32 \%$ of the temperature effect (average $\Delta T$ at $\mathrm{N}-1, \mathrm{~N}-2$, and N-3) of the ground floor, respectively. By contrast, the cold exhaust from the outer two columns registered $91 \%$ of the temperature effect of the inner two columns (Appendix 2). Here, we introduce an index of the effective amount of cold exhaust $H_{e}(\mathrm{kw})$, which is obtained by multiplying the total amount of cold exhaust $H_{n}$ by a coefficient that considers the difference in temperature effects due to the location of the exhaust outlet as (when $n>0$ ):

$$
H_{e}=\left[\left(n_{G}+0.44 n_{M}+0.32 n_{T}\right) / n\right]\left[\left(n_{I}+0.91 n_{O}\right) / n\right] H_{n},
$$

where $n_{G}, n_{M}$, and $n_{T}$ are the numbers of operating units on the ground floor, middle floor, and top floor, respectively; and $n_{I}$ and $n_{O}$ are those in the inner (\#2 and \# 3) and outer (\#1 and \#4) columns. The term "effective amount of cold exhaust" refers to the amount of cold exhaust effective in cooling the ambient air at specific measurement points. In this case, $H_{e}$ was defined as the amount of cold exhaust that affects the average $\Delta T$ at three measurement points ( $\mathrm{N}-1$, $\mathrm{N}-2$, and N-3). The purpose of using the average of three points was to minimize the effect of the spatial variation of $\Delta T$. Weighting factors were used in Eq. (2) to adjust the temperature sensitivity to cold exhaust from each emission location such that it was equivalent to the units on the ground floor in the inner columns under the same weather conditions. By using $H_{e}$ instead of $H_{n}$, the temperature sensitivity $\left(\Delta T / H_{e}\right)$ could be qualitatively evaluated without being influenced from the spatial diversity of the emission locations. Figure 3 shows that the pattern of the time variation of the average $H_{e}$ for each observation period is nearly proportional to that of $H_{n}$ for each period, with a peak value of -16.1 at 5:30 a.m. in summer, and -16.0 , at 4:10 a.m. in winter.

\section{Results and discussion}

\subsection{Spatial distribution of the cooling effect}

Figure 4 shows the time series of the effect of cold exhaust on air temperatures $(\Delta T)$ at each measurement point of $1.5 \mathrm{~m}$ height, for each observation period. The purpose of this analysis was to identify the general characteristics of the diurnal variation and spatial distribution of $\Delta T$, independent of atmospheric conditions, and discuss its relationship with cold heat. Therefore, the effects from the day-to-day variation in $\Delta T$ were excluded through utilizing seasonal
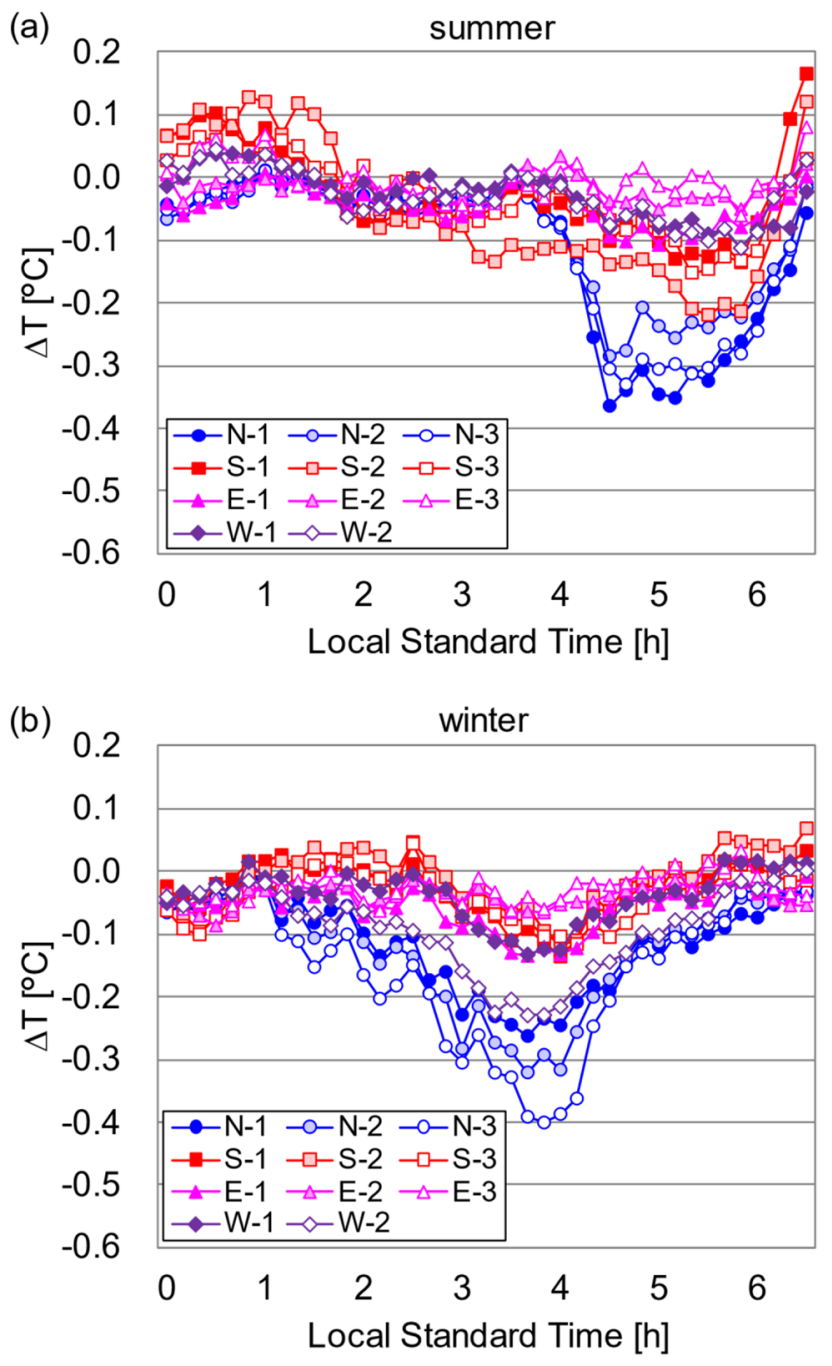

Fig. 4 Average effect of cold exhaust on average 1.5-m air temperatures $(\Delta T)$ at each measurement point for each observation period: a summer and $\mathbf{b}$ winter

averaging. The temperature decline was indicated around 4:00 - 6:30 a.m. for summer and 1:30-6:30 a.m. for winter, which coincides with the operation time of the ASHPWHs. It can also be confirmed that the temperature decline is the greatest on the northern side of the site with the largest number of cold exhaust emission sources. At each of the three measurement points on the northern side, the value of $\Delta T$ is larger than those at all the other points in other directions. In the summer, among the three points on the northern side, the western point $\mathrm{N}-1$ shows the largest $\Delta T$ of $-0.36^{\circ} \mathrm{C}$ at $4: 30$ $\mathrm{am}$; in the winter, the eastern point $\mathrm{N}-3$ shows the largest $\Delta T$ of $-0.40{ }^{\circ} \mathrm{C}$ at 3:50 a.m. Referring to the average operation status of each ASHPWH unit (Fig. 2), a rough relationship can be observed between the horizontal distribution of the number of operating units and $\Delta T$ on the northern side. At the summer peak time (4:30 a.m.), the average number of 
units operating in the western columns (\#1 and \# 2) was 2.5, which is 1.25 times larger than the number (2.0) in the eastern columns (\#3 and \#4). At the winter peak time (3:50 a.m.), the average number of units operating in the eastern columns was 5.0, which is 1.32 times larger than the number (3.8) in the eastern columns. Therefore, larger $\Delta T$ values are observed at the measurement points with a larger number of operating units in the vicinity.

However, $\Delta T$ was affected by the linear distance between the emission source and the measurement point, and by complex factors, such as local airflow caused by obstacles (e.g., buildings, fences, and plants). The linear distance could be observed, whereas the complex factors could not be observed. A detailed quantitative examination of these factors is highly site-specific and beyond the scope of this study. The following discussion focuses on the northern side of the site, where $\Delta T$ at the $\mathrm{N}-1, \mathrm{~N}-2$, and $\mathrm{N}-3$ measurement points, and the effective amount of exhaust heat $\left(H_{e}\right)$ were used in qualitative analyses. This was carried out to identify the meteorological factors affecting $\Delta T$, independent of spatial location. To this end, the effect of spatial variability in $\Delta T$ was eliminated by averaging the values at these three measurement points. The peak value of the average $\Delta T\left({ }^{\circ} \mathrm{C}\right)$ on the northern side of the building is -0.32 , for summer (at 4:30 a.m.) and winter (at 3:40 a.m.). The effective amounts of cold exhaust $H_{e}(\mathrm{~kW})$ at each peak time are -11.4 and -14.8 in summer and winter, respectively (Fig. 3); thus, the sensitivities of temperature to cold exhaust $\left(\Delta T / H_{e}\right)\left({ }^{\circ} \mathrm{C} /\right.$ $\mathrm{kW})$ are 0.028 and 0.022 , respectively. The differing $\Delta T /$ $H_{e}$ values for each season could be due to the difference in the atmospheric conditions during each observation period.

Figure 5a shows the time series of the average $\Delta T$ measured at the northern points $(\mathrm{N}-1, \mathrm{~N}-2$, and $\mathrm{N}-3)$ and averaged for each wind direction and season. The $\Delta T\left({ }^{\circ} \mathrm{C}\right)$ values at peak times are -0.71 (at 5:00 a.m.), -0.24 (at 4:40 a.m.), and -0.32 (at 3:40 a.m.) for days with southerly wind and summer and winter days with northerly wind, respectively. The cooling effect was significantly larger when the southern winds were dominant in the summer, and the thermal environment worsened, perhaps because southerly wind speeds tend to be low; thus, the diffusion of the cold exhaust is more difficult, and the exhaust tends to stay near the ground at the site.

Figure $5 \mathrm{~b}$ shows the time series of the sensitivity of temperature to cold exhaust $\left(\Delta T / H_{e}\right)$. At each peak time of $\Delta T$, the values of $\Delta T / H_{e}\left({ }^{\circ} \mathrm{C} / \mathrm{kW}\right)$ are 0.055 (at 5:00 a.m.), 0.019 (at 4:40 a.m.), and 0.022 (at 3:40 a.m.) for days with southerly wind and summer and winter days with northerly wind, respectively. The value of $\Delta T / H_{e}$ is significantly larger for southerly wind days in the summer when the average wind speed is small (Table 1), indicating dependence on wind direction and wind speed. For northerly wind days, the value of $\Delta T / H_{e}$ is slightly greater in winter, despite a
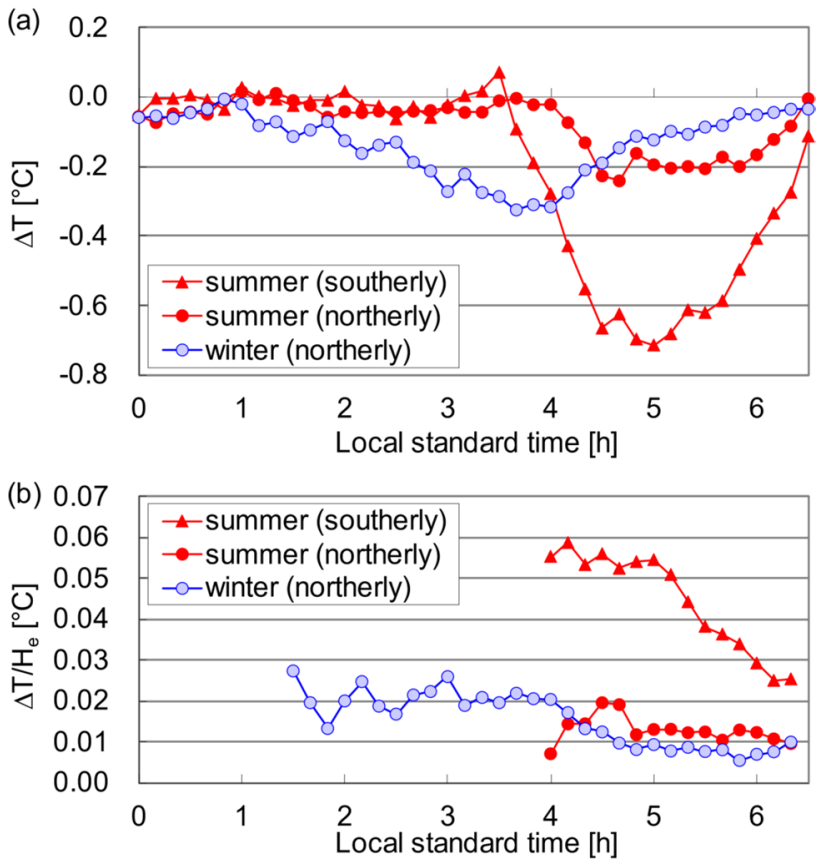

Fig. 5 a Average of the effect of cold exhaust on air temperatures $(\Delta T)$ at three measurement points $(\mathrm{N}-1, \mathrm{~N}-2$, and $\mathrm{N}-3)$ on the northern side of the site (sorted by observation period and wind direction). b The sensitivity of temperature to cold exhaust $\left(\Delta T / H_{e}\right)$

slightly greater wind speed, suggesting that dependence on other factors, such as the convective stability near the ground surface. The value of $\Delta T / H_{e}$ tends to be large immediately after the units start operating (and $H_{e}$ is still small) and gradually decreases as $H_{e}$ increases (Fig. 3). Therefore, $\Delta T$ peaks before $H_{e}$. This is because, as the temperature near the ground decreases, the density difference between the cold exhaust and the air temperature decreases, making it harder for the cold exhaust to sink downward and to increase its advection-diffusion to the surroundings. Focusing on the limited space within the site reveals that, as $H_{e}$ input increases, the ratio of $H_{e}$ going out by advection-diffusion also increases, decreasing the sensitivity of temperature to cold exhaust $\left(\Delta T / H_{e}\right)$. Thus, a value of $H_{e}$ must exist that can achieve the desired $\Delta T$ with maximum efficiency, suggesting that the cooling effect can be sustained for a longer time by adjusting $H_{e}$ by controlling the number of operating units.

During the entire period of observation, August 20, 2008, marked the largest $\Delta T$ observed at 5:00 a.m., with calm wind (wind speed $<0.4 \mathrm{~m} / \mathrm{s}$ ) and air temperature $\left(T_{a}\right)$ measured at the rooftop of $25.2{ }^{\circ} \mathrm{C}$. Near the peak time, all measurement points $1.5 \mathrm{~m}$ above ground level on the northern side of the building registered $\Delta T$ of more than $-1{ }^{\circ} \mathrm{C}$, and all other measurement points at a $1.5-\mathrm{m}$ height showed $\Delta T$ values of $-0.4{ }^{\circ} \mathrm{C}$ to $-0.6{ }^{\circ} \mathrm{C}$ (Fig. 6a). At 5:00 a.m., five of the 12 ASHPWH units on the northern side of the building (G-1, M-2, G-2, M3, and T-4) were in operation (Fig. 6b). The 


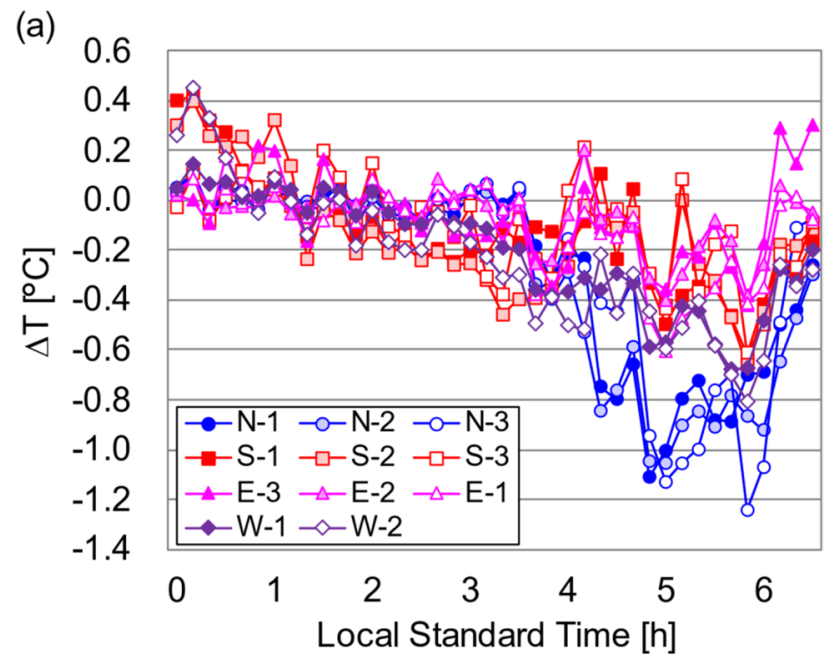

(b)

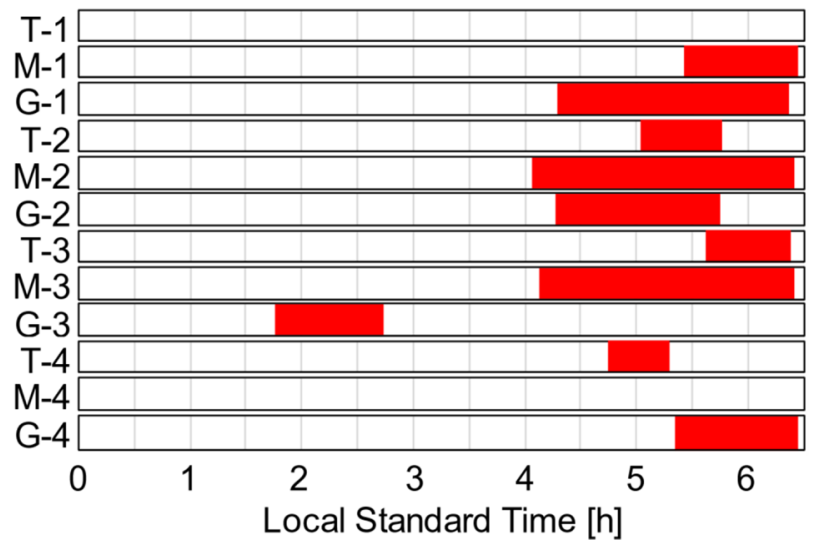

Fig. 6 a Effect of cold exhaust on air temperatures $(\Delta T)$ observed at each measurement point of $1.5-\mathrm{m}$ height; $\mathbf{b}$ operation status of each ASHPWH unit on the northern side of the building, on August 20, 2008

observed horizontal distribution of $\Delta T$ was roughly reproduced using a CFD simulation (see Appendix 2). Figure 6 shows that the magnitude of $\Delta T$ at each measurement point is not simply determined by the number of operating units in the vicinity. For example, at 5:40 a.m., the number of units in operation reaches 8 ; however, the $\Delta T$ values observed at the three northern points range from -0.8 to $-0.7^{\circ} \mathrm{C}-$ approximately $74 \%$ of the value at 5:00 a.m. Immediately after that, two units stopped, and at 5:50 a.m., three units were in operation in the western columns (\#1 and \#2) and the eastern columns (\#3 and \#4); however, a significant $\Delta T$ of over $-1.2{ }^{\circ} \mathrm{C}$ was observed only at the eastern point $(\mathrm{N}-3)$. Thus, the relationship between the linear distance from the emission source and $\Delta T$ at each measurement point was not evident in the observations from this day. As previously discussed, this relationship was roughly confirmed by seasonally averaged observations. As such, the irregularities

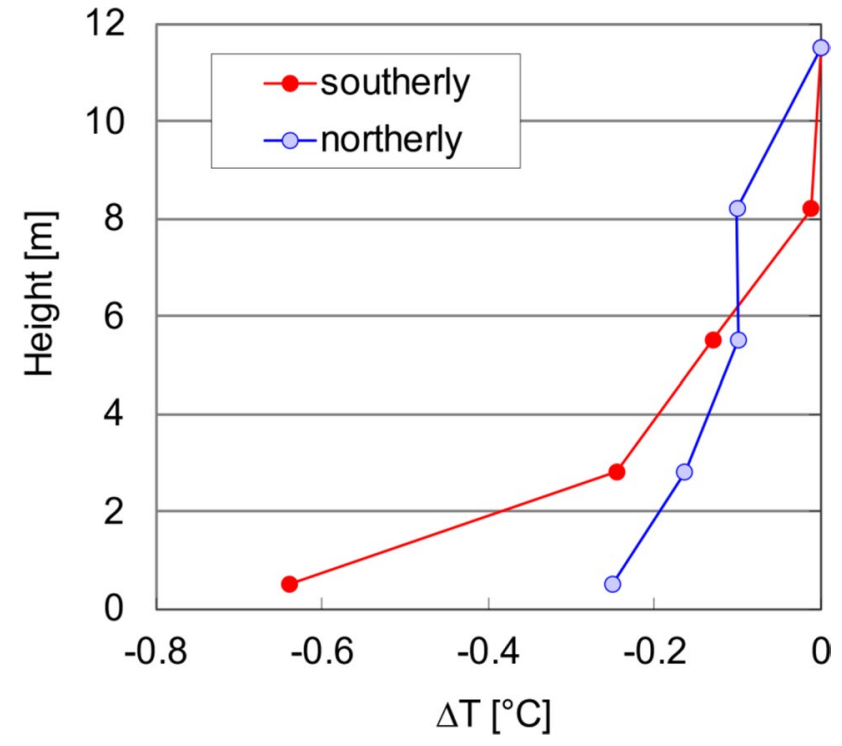

Fig. 7 Vertical profile of the average effects of cold exhaust on temperature $(\Delta T)$ along the north side of the building at 5:00 a.m. in the summer observation period (sorted by main wind direction)

observed on this specific day were considered temporary phenomena attributable to more complex local airflow that could not be captured by the measurements in this study.

Figure 7 shows the vertical profile of the $\Delta T$ as of 5:00 a.m. in the summer, determined for each wind direction from the average value for each height at each temperature measurement point along the north-side wall of the building. On the southerly wind days, $\Delta T$ is extremely large near the ground, but that influence decreases rapidly with height, leaving little observable $\Delta T$ at a height of $8.2 \mathrm{~m}$. On the other hand, during days with northerly winds, the $\Delta T$ near the ground is relatively small, but the rate of decline with height is also small, showing a more substantial $\Delta T$ at $8.2 \mathrm{~m}$ height than on southerly wind days. This vertical structure shows that, in the case of weaker southerly winds, cold exhaust is hardly diffused (partly because it is sheltered from the winds by the building), effectively cooling the air near the ground. However, when relatively strong northerly winds blow, cold exhaust is diffused upward along the north-side wall of the building; therefore, the cooling effect near the ground is reduced.

\subsection{Dependence of the cooling effect on local atmospheric conditions}

Since the cold exhaust is heavier than the ambient air, it naturally sinks downward, and then spreads outward along the ground surface driven by its own weight. Its diffusion speed is likely affected by the local atmospheric conditions. Wind speed is one of the major factors that influence the horizontal advection of the cold. Wind direction is another 
influencing factor that defines the positional relationship between the building and emission source of the cold. In addition, the near-surface thermal convection is thought to affect the vertical diffusion of the cold.

Figure 8 a shows the relationship between the sensitivity of the $1.5-\mathrm{m}$ temperature to cold exhaust $\left(\Delta T / H_{e}\right)$ and wind speed (1-h average prior to peak $\Delta T$ ). $\Delta T$ is the average of the observed values at the $\mathrm{N}-1, \mathrm{~N}-2$, and $\mathrm{N}-3$ measurement points. The figure clearly demonstrates that the weaker the wind is, the greater the $\Delta T / H_{e}$ becomes. Considering that the UHI tends to be more intense on calm days, this could be advantageous from the perspective of improving the thermal environment. If we focus on the northerly wind days, the locations of the summer and winter clusters overlap for the most part, and seasonal differences are hardly observed in the range of $\Delta T / H_{e}$. On the other hand, the cluster of southerly wind during the summer is found at a location away from the other two clusters indicating a higher sensitivity. This is likely due to the influence of the positional relationship between the building and the emission sources of the cold in addition to the wind speed. That is to say, when the exhaust outlets are placed on the leeward side of the building, the wind has less effect on the diffusion of the cold because the building acts as a shelter
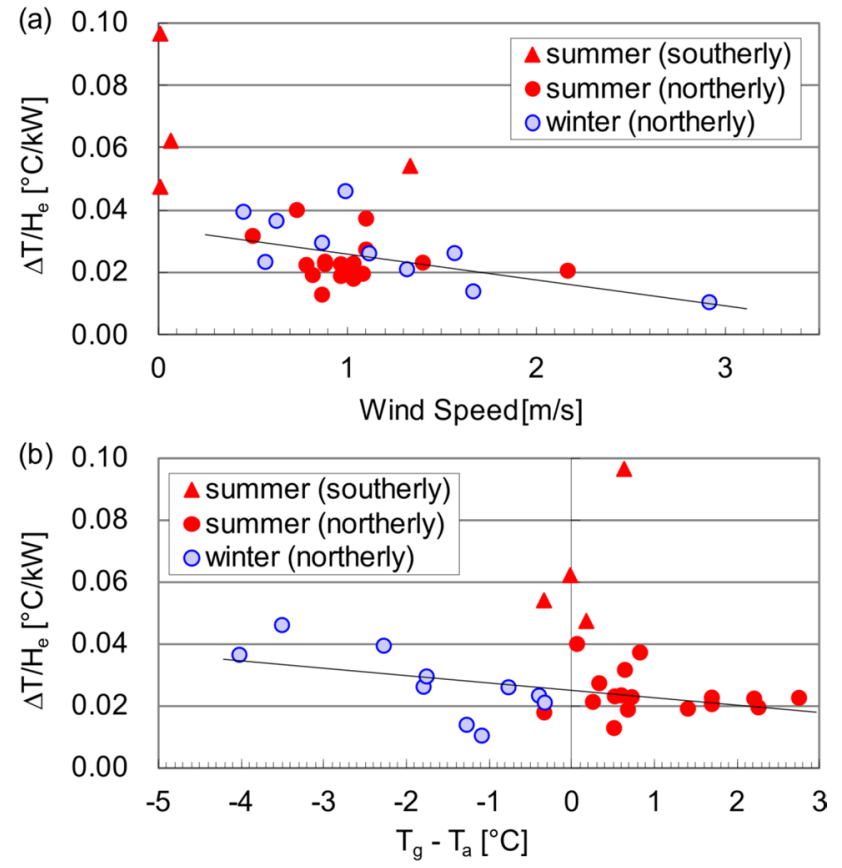

Fig. 8 Relationship between the sensitivity of temperature to cold exhaust $\left(\Delta T / H_{e} ; 10\right.$-min average taken at the peak time of $\Delta T$ for each day) and the meteorological factors (1-h average prior to the peak time): $\mathbf{a}$ wind speed and $\mathbf{b}$ difference between the air temperature and ground surface temperature $\left(T_{g}-T_{a}\right)$. The value of $\Delta T$ is the average of those observed at points $\mathrm{N}-1, \mathrm{~N}-2$, and $\mathrm{N}-3$. The straight lines represent linear regression of data on days with northerly wind from the wind. In this case, since the location of the outlets is mainly on the northern side of the building, we can expect the $\Delta T / H_{e}$ to become greater under southerly winds.

As an indicator for convective stability near the ground, we used the difference between the air temperature and ground surface temperature $\left(T_{g}-T_{a}\right)$. Figure $8 \mathrm{~b}$ shows, in the same manner as in Fig. 8a, the relation between $\Delta T / H_{e}$ and $T_{g}-T_{a}$. The locations of summer and winter clusters hardly overlap in the range of $T_{g}-T_{a}$ clearly indicating that it was mostly unstable $\left(T_{g}>T_{a}\right)$ or neutral $\left(T_{g} \approx T_{a}\right)$ during the summer, while it was always stable $\left(T_{g}<T_{a}\right)$ during the winter. In the range of $\Delta T / H_{e}$, the cluster of southerly wind is located above the other two clusters of northerly wind, as found in Fig. 8a. On days with northerly winds, $\Delta T /$ $H_{e}$ shows a slight tendency to increase as $T_{g}$ drops below $T_{a}$, suggesting that the near-surface convective stability state slightly influences the diffusion of the cold exhaust at the building scale; however, this influence is small compared to that of the wind. This can be understood that since the cold exhaust near the building is much cooler (and heavier) than ambient air, the downward momentum of its gravity-driven flow is too large to be affected by the buoyancy forces from the weak thermal convection near the ground at night.

Figure 8 suggests that the wind (horizontal advection) has a substantial influence on the sensitivity $\Delta T / H_{e}$, while the influence from near-surface thermal convection is limited. To test the statistical significance of this result, we performed a multiple regression analysis with $\Delta T / H_{e}$ as a target variable and the three influencing factors (i.e., wind direction, wind speed and $T_{g}-T_{a}$ ) as explanatory variables. Here, wind direction is represented by a dummy variable that takes on the value 0 for south or 1 for north. The result (Table 2) confirmed that the most significant influencing factor is wind direction $(p<0.001)$ followed by wind speed ( $p=0.013)$, and that $T_{g}-T_{a}$ has no significant influence $(p=0.062)$. Here, a $p$ value less than 0.05 was considered statistically significant.

Table 2 Result of multiple regression analysis among the influencing factors on the $\Delta T / H_{e}\left({ }^{\circ} \mathrm{C} / \mathrm{kW}\right)$ shown in Fig. 8. Wind direction is represented by a dummy variable that takes on the value 0 for south or 1 for north

\begin{tabular}{lll}
\hline Explanatory variable & $\begin{array}{l}\text { Partial regression coef- } \\
\text { ficient }\end{array}$ & $p$ value \\
\hline Intercept & $6.8 \times 10^{-2}$ & $6.5 \times 10^{-14}$ \\
Wind direction & $-3.4 \times 10^{-2}$ & $2.0 \times 10^{-6}$ \\
Wind speed $(\mathrm{m} / \mathrm{s})$ & $-8.9 \times 10^{-3}$ & $1.3 \times 10^{-2}$ \\
$T_{g}-T_{a}\left({ }^{\circ} \mathrm{C}\right)$ & $-2.2 \times 10^{-3}$ & $6.2 \times 10^{-2}$ \\
$R^{2}$ & 0.73 & $(p<0.001)$ \\
\hline
\end{tabular}




\section{Conclusions}

Around a low-rise apartment building in which all apartments have air-source heat pump water heaters (ASHPWHs) installed, we observed the thermal environment in building scale during summer and winter. The following findings concerning the cooling effect of cold exhaust on ambient outdoor temperature are provided as:

(1) The greatest reduction in $1.5 \mathrm{~m}$ air temperature exceeded $1{ }^{\circ} \mathrm{C}$ and it was shown to be concentrated on the side where the exhaust outlets of ASHPWH were placed. A building-scale improvement in the outdoor thermal environment caused by the cold exhaust was clearly demonstrated.

(2) The outdoor cooling effect of the cold exhaust showed a tendency to increase when the exhaust outlets were placed on the leeward side of the building.

(3) The cooling effect also showed a tendency to increase when winds were weak. Since it was observed that the UHI becomes more intense on calm days, it is an advantage from the viewpoint of UHI alleviation.

(4) The thermal convective stability near the ground surface showed no significant influence over the cooling effect.

As calm days with weak wind were minimal during the entire measurement period of this study, and no southerly wind days were observed during the winter, the study would benefit from further accumulation of data through additional observation cases. In this study, the temperature measurement points were limited within the site of the target building. To estimate the cooling effect of the cold exhaust beyond the boundary of the site, a city-block scale observation is required. It is possible that the convective stability state near the ground surface has some influence over the cooling effect in city-block (or wider) scale.

Although this study focused on the direct impact on the outdoor thermal environment induced by ASHPWHs, its indirect impact on the annual energy consumption is also an interesting research topic. The reduction in outdoor temperature is likely to decrease the cooling load in summer and increase the space heating load in winter. The observations from this study show that the winter temperature effect is the same as that in summer; this suggests that the impact on the increased space heating loads would be limited compared to the major contribution from significantly reduced energy consumption for water heating, as shown in a previous simulation study (Yamaguchi et al. 2009). As data on energy demand were not available, assessing the impact on annual energy demand is a recommended future research topic.
The findings from this study provide a new perspective for the urban planning and architectural design of residential areas. The large temperature drop near buildings induced by the cold exhaust from ASHPWHs is beneficial in terms of improving the indoor thermal environment by introducing outdoor air through natural or mechanical ventilation. The indices, $H_{e}$ and $\Delta T / H_{e}$, may be utilized to establish optimal strategies to capitalize on its cooling potential. The observed results confirm that the temperature decrease was greater in locations closer to the exhaust outlet in the vertical and horizontal directions. Based on this information, there is an ability to optimize the placement of outdoor units, windows, or air supply openings in the house. This is a strategic approach to maximize the effective amount of cold exhaust $\left(H_{e}\right)$. The locations and orientation of residential buildings and outdoor units of ASHPWHs may be planned by considering the prevailing wind direction in summer nights to maximize the cooling effect of the cold exhaust; this approach maximizes temperature sensitivity to cold exhaust $\left(\Delta T / H_{e}\right)$. At the city-block scale, the layout of residential buildings may be designed to capitalize on cold exhaust by storing it in spaces between buildings such as courtyards; alternatively, windows or air supply openings may be placed leeward of the outdoor unit.

Although each ASHPWH has a short operational duration, it is greatly advantageous to be able to set the time frame to suit the purpose. The analysis of temperature sensitivity to cold exhaust shows that when many units are operating concurrently, the rate of clod exhaust loss outside the site due to advection-diffusion increases, and the cooling efficiency within the site decreases. This suggests that the cooling effect near the building may be sustained over a longer duration by controlling the number of operating units; this is yet another approach to maximize temperature sensitivity $\left(\Delta T / H_{e}\right)$. Alternatively, in terms of sleep quality, ASHPWHs may be programmed to operate concentrically during earlier (and hotter) nighttime occasions. This is because humid heat exposure during the initial sleep segment may be more disruptive to sleep and thermoregulation compared with the same exposure during later sleep segments (Okamoto-Mizuno et al. 2005a). If adequate sleep may be maintained during the first half of sleep, then it is unlikely to be degraded despite deterioration of the thermal environment during the latter half of sleep (Okamoto-Mizuno et al. 2005b). Theoretically, the temperature effect of cold exhaust is smaller earlier on in the nighttime as the thermal convective state near the ground surface is more unstable than later in the nighttime. However, the factor analysis results show that the contribution of the convective stability to temperature sensitivity is insignificant at the building scale.

As discussed in the introduction, heat-related mortality and morbidity are closely related to nighttime outdoor temperatures. Thus, the damage function based on 
epidemiological studies may be used to quantitatively assess the health benefits attributable to decreased nighttime temperatures. Previous studies evaluated the nighttime health damage on a daily basis by using representative temperature of nighttime hours as the explanatory variable of the damage function. For example, this includes the daily minimum temperature (Ohashi et al. 2014), or temperature at 0:00 (Narumi et al. 2016) or 22:00 (Kuwayama et al. 2019). However, this approach is not appropriate for assessing the effect of large temperature reductions within specific time frames induced by cold exhaust from ASHPWHs. As such, it is necessary to develop new evaluation methods, such as using multiple damage functions made separately for each hour.

The cold exhaust from the AHPWHs has enough potential to maintain a good indoor thermal environment throughout sleeping hours; however, it is currently diffused outside the site without being fully utilized. The primary contribution of this paper is to provide the first clue for future research to understand the characteristics of cold exhaust and exploit its full potential. Although this study focused on buildingscale effects, if ASHPWH became widespread, it is expected that city-scale effects may manifest. In a large-scale residential complex area, the cold flowing from each site would be complementary to form a more extensive urban cool spot. In such cases, the synergistic effects with typical UHI measures aimed at reducing surface temperature, such as greening and water-retentive pavements, may be expected (Yamaguchi et al. 2016). This can be explained as a result of the stabilization of the atmosphere due to the decrease in surface temperature, which suppresses the diffusion of cold exhaust. As UHI is formed by multiple factors, it is difficult to address using a single solution. Combining multiple solutions to achieve a collective effect is the most rational approach to improving the thermal environment of a city. The area-wide installation of ASHPWHs is a promising option in such a comprehensive countermeasure portfolio.

In megacities of developing countries located in tropical regions, further degradation of the urban thermal environment will occur as a result of global warming and UHI, and energy demand for air conditioning and hot water is expected to increase rapidly. These megacities are promising candidates where the outdoor cooling effect of ASHPWHs will be most effective and beneficial. In the tropics, neither poor performance from low temperatures is likely to occur nor is there an impact on space heating energy due to the outdoor cooling effect. Urban heat is unused energy that is abundant in cities; the by-product of its use is also reusable cold energy. By recovering excess urban heat, ASH$\mathrm{PWH}$ reduces $\mathrm{CO}_{2}$ emissions while meeting rapidly growing energy demand, and improving the deteriorated nighttime thermal environment. The urban-scale cascading use of excess heat and cold energy afforded by ASHPWHs should be considered a potential method to mitigate and adapt to climate change.

\section{Appendix}

\section{Appendix 1. Measurement of exhaust air from outdoor unit}

This observational study had many limitations, as it was conducted on a real house, and directly measuring the power consumption of each ASHPWH unit or the temperature and airflow of the exhaust was not possible. Therefore, the temperature and air velocity of the cold exhaust from the units were measured separately to verify the energy of the cold exhaust.

The measurements were performed on March 12, 2009, when the wind was weak, at an experimental house located in Yokohama City, Kanagawa Prefecture. The ASHPWH unit used for the measurements was of the same type (Corona, CHP-452) as the ones used in this study. The outdoor unit was installed on the ground beside the house, and the center of the air outlet was located at approximately $0.5 \mathrm{~m}$ above the ground.

Thermistor thermometers (T\&D, RTR-52) fitted with solar shields were used to measure the ambient temperature, intake, and exhaust air. The air outlet of the outdoor unit featured a concentric circular opening with an outer diameter of $440 \mathrm{~mm}$ and an inner diameter of $110 \mathrm{~mm}$. To capture the temperature distribution of the exhaust within the blowing area at the air outlet, four measurement points $(U, D, L$, and $R$ ) were fixed on the upper, lower, left, and right sides of the area, each approximately $140 \mathrm{~mm}$ from the center. Intake air temperatures $\left(T_{\text {in }}\right)$ were measured at two points near the inlet of the outdoor unit, and the averaged values were used for the analysis. The ambient air temperatures were measured at $1.5 \mathrm{~m}$ above the ground and approximately $5 \mathrm{~m}$ horizontally from the outdoor unit side. The data measurement interval for the thermistor thermometer was set to $15 \mathrm{~s}$, and the average value of over $1 \mathrm{~min}$ was used to analyze the results.

A rotating vane anemometer (TSI, Model 5725) was used to measure the air velocity of the exhaust air. Using the same method as for air temperature, the air velocity was measured at four points $(U, D, L$, and $R)$ in the vertical and horizontal directions from the center of the air outlet. The measurement interval and time constant (averaging period) were set to 1 and $10 \mathrm{~s}$, respectively, and the reading was taken when the fluctuation of the displayed value had settled.

Figure 9 shows the air temperature measurements taken from 9:15 a.m. to 13:40. The ASHPWH unit started at 9:23 a.m. and stopped at 13:28. The intake air temperature remains approximately $0.8{ }^{\circ} \mathrm{C}$ lower than the ambient 
Fig. 9 Time series of the temperature of the ambient air, the intake, and the exhaust of the outdoor unit. The exhaust temperatures are measured at points $\mathrm{U}, \mathrm{L}, \mathrm{R}$, and $\mathrm{D}$

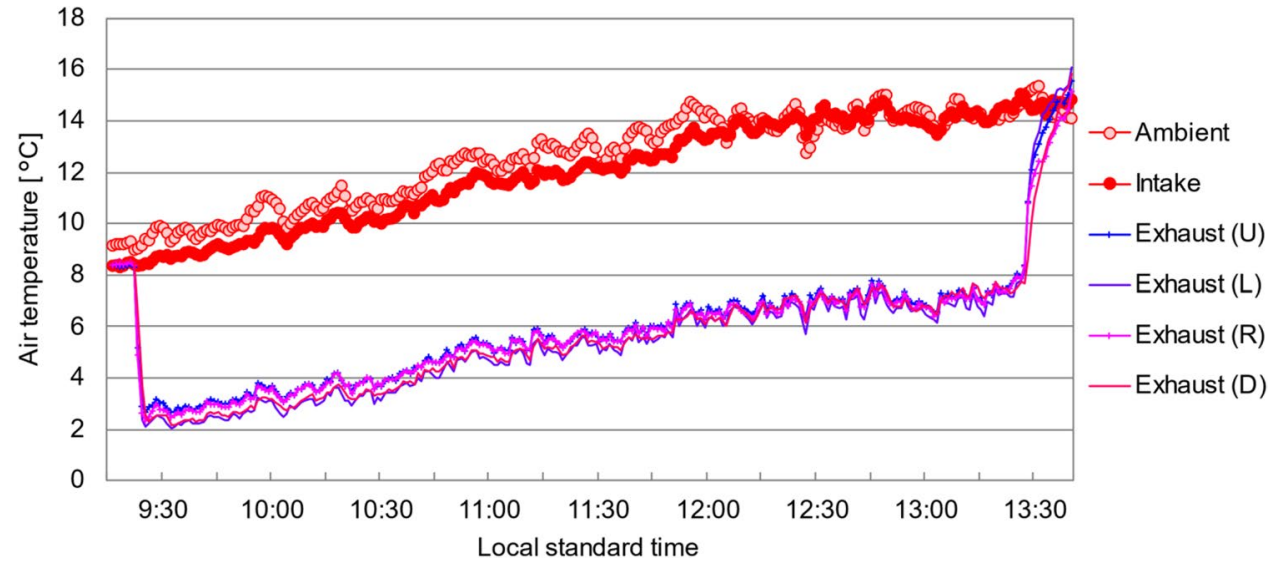

temperature during the morning but rises approximately $6.4{ }^{\circ} \mathrm{C}$ with the ambient temperature throughout the operating time of the unit, with no notable effect from the cold exhaust. The exhaust temperature readings at all four points decrease significantly as soon as the unit starts. Thereafter, they rise in sync with the ambient air temperature and quickly return to the same level as the ambient air temperature when the unit stops. Throughout the operating time of the unit, the deviations from the intake air temperature remained nearly constant. During the morning, the values at $U$ and $R$ were approximately $0.5^{\circ} \mathrm{C}$ higher than the values at $D$ and $L$, indicating slight temperature irregularities within the blowing area of the air outlet. However, because the values at $U$ and $R$ and those at $D$ and $L$ are in good agreement, the four-point average is regarded as the average temperature of the entire exhaust. By averaging the temperature deviation from the intake air temperature throughout the unit operation time $(9: 16$ am $-13: 40)$, a four-point average of $-6.75^{\circ} \mathrm{C}$ was obtained.

The air velocity of the exhaust air was measured separately from the air temperature. The values of air velocity $(\mathrm{m} / \mathrm{s})$ obtained at measuring points $U, D, L$, and $R$ were 3.4, $3.3,3.3$, and 3.1, respectively. Here, the four-point average of $3.26 \mathrm{~m} / \mathrm{s}$ is considered the average velocity of the exhaust air immediately after leaving the vent.

The amount of energy of the cold exhaust from an ASHPWH unit $H_{l}(\mathrm{~kW})$ can be expressed as:

$H_{1}=E-Q$,

where $E$ and $Q$ represent the electricity consumption (kW) and heating capacity $(\mathrm{kW})$ of the ASHPWH, respectively. According to the rated values specified by the manufacturer, $Q$ is a constant value of 4.5 , and $E$ depends on the outdoor temperature, humidity, supply water temperature, and hot water temperature (Table 3). Because the data available for this study are limited, only the outdoor dry-bulb temperature is considered, assuming that the hot water temperature was set at $65^{\circ} \mathrm{C}$. The electric consumption $E$ can be approximated by a linear equation of the air temperature $T_{a}(\mathrm{~K})$ $\left(R^{2}>0.999\right)$ as follows:

$E=-0.0128 T_{a}+4.83$.

In the measurement, the average intake air temperature $T_{a}$ during the operation of the ASHPWH unit was $285.16 \mathrm{~K}$ $\left(12{ }^{\circ} \mathrm{C}\right)$. Therefore, the average value of $H_{1}$ can be estimated at $-3.32 \mathrm{~kW}$ from Eqs. (3) and (4).

Using the measured air temperature values of the exhaust $T_{e x}(\mathrm{~K})$ and its air velocity $V(\mathrm{~m} / \mathrm{s}), H_{1}(\mathrm{~kW})$ can be expressed as:

$H_{1}=\rho C_{p}\left(T_{\mathrm{ex}}-T_{a}\right) V A / 1000$

$\rho=P /\left(R T_{a}\right)$,

where $\rho, C_{p}, A, P$, and $R$ are the density of air $\left(\mathrm{kg} / \mathrm{m}^{3}\right)$, constant pressure heat capacity of air $(1004 \mathrm{~J} / \mathrm{kg} / \mathrm{K})$, effective blowing area of the air outlet $\left(\mathrm{m}^{2}\right)$, atmospheric pressure (101,300 Pa), and gas constant of dry air $(287 \mathrm{~J} / \mathrm{kg} / \mathrm{K})$, respectively. The air velocity is generally not constant within the blowing area, as it is smaller near the outer edge and the rotation axis of the fan; thus, the effective blowing area is

Table 3 Heating capacity and electric consumption of the ASHPWH unit under conditions specified by the manufacturer

\begin{tabular}{lllll}
\hline Outdoor dry-bulb temperature $\left({ }^{\circ} \mathrm{C}\right)$ & 25 & 16 & 7 & 7 \\
\hline Outdoor wet-bulb temperature $\left({ }^{\circ} \mathrm{C}\right)$ & 21 & 12 & 4 & 6 \\
Supply water temperature $\left({ }^{\circ} \mathrm{C}\right)$ & 24 & 17 & 9 & 9 \\
Hot water temperature $\left({ }^{\circ} \mathrm{C}\right)$ & 65 & 65 & 65 & 90 \\
Heating capacity $(\mathrm{kW})$ & 4.5 & 4.5 & 4.5 & 4.5 \\
Electricity consumption $(\mathrm{kW})$ & 1.02 & 1.14 & 1.25 & 1.54 \\
\hline
\end{tabular}


assumed to be smaller than the actual size of the vent aperture. Here, we assume that $A$ is $0.121 \mathrm{~m}^{2}$, which corresponds to the area of the region between the concentric circles with diameters of 436 and $189 \mathrm{~mm}$, which is approximately $85 \%$ of the size of the air outlet aperture. Furthermore, using $T_{e x}$ - $T_{a}(-6.75 \mathrm{~K}), T_{a}(285.16 \mathrm{~K})$, and $V(3.26 \mathrm{~m} / \mathrm{s})$ obtained from the measurements, $H_{l}$ was calculated from Eqs. (5) and (6), yielding a value of $-3.31 \mathrm{~kW}$. The value obtained here is in good agreement with the value of $H_{l}(-3.32 \mathrm{~kW})$ calculated from Eqs. (3) and (4). Therefore, based on the measured values of temperature and air velocity, the amount of energy of the cold exhaust roughly corresponds to the estimated values of the heating capacity and electric consumption specified by the manufacturer.

\section{Appendix 2. Computational fluid dynamics (CFD) simulation}

In this study, the number of temperature measurement points was too small to produce high-resolution 3-dimensional images of air temperature distribution around the building. The spatially dispersed distribution of emission sources makes the evaluation of temperature sensitivity to cold exhaust even more difficult. The intake temperature of each outdoor unit, to estimate the amount of cold exhaust, was not monitored. The location of the measurement points was limited to the site of the target building; hence, estimating the cooling effect of the cold exhaust beyond the boundary of the site was not possible. In this appendix, a computational fluid dynamics (CFD) simulation was performed to reproduce the results of the observation. This simulation study has the following four primary objectives: (1) visualizing a 3-dimensional distribution of air temperature around the building to better understand the behavior of the cold exhaust emitted from the outlets; (2) evaluating the relative effect of the vertical and horizontal locations of the exhaust outlets on the temperature at specified measurement points; (3) evaluating the effect of reduced intake temperature due to cold exhaust on the estimated amount of the cold exhaust itself; and (4) understanding the impact of the cold exhaust beyond the boundary of the site.

We attempted to reproduce the observed results from August 20, 2008, at 5:00 a.m. (Fig. 6), with a three-dimensional simulation using a standard $k-\varepsilon$ turbulence flow model (AKL FlowDesigner 2020). The analysis area was $314 \mathrm{~m}$ east-west $\times 375 \mathrm{~m}$ north-south $\times 25 \mathrm{~m}$ vertical, with 4.0 million mesh elements $(200 \times 200 \times 100)$. The target building, site boundary, and outdoor units of the ASHPWH were set as shown in Fig. 2. Two 2-m-high fences with 0\% opening ratio were placed on the north and south boundaries of the site; those with $90 \%$ opening ratio were on the east and west boundaries. Surrounding buildings were selected after considering their influence on the airflow. The inflow

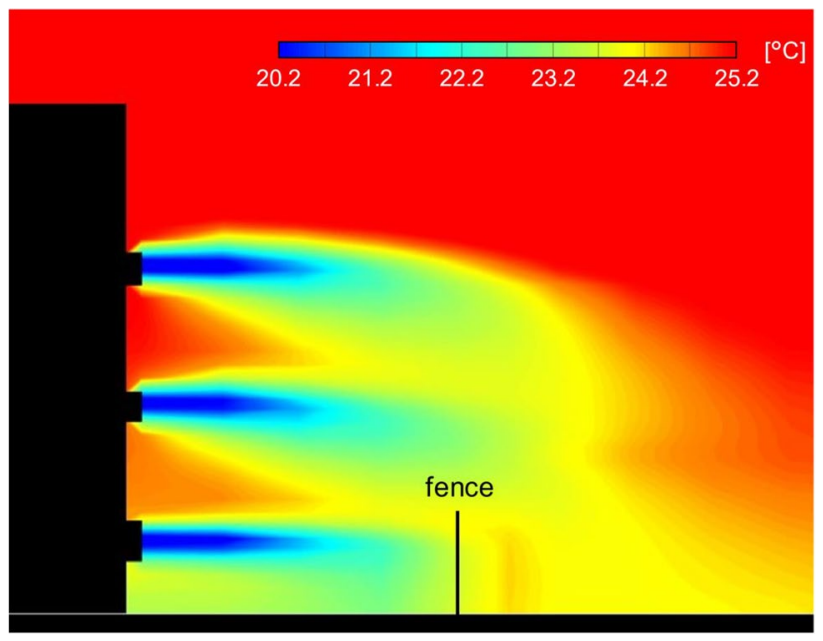

Fig. 10 Simulated vertical cross-section of air temperature distribution along cold exhaust outlets

boundary conditions included a southerly wind at $1 / 4$ low power with a speed of $0.1 \mathrm{~m} / \mathrm{s}$ at an altitude of $11.5 \mathrm{~m}$ and temperature of $25.2^{\circ} \mathrm{C}$. The temperature of the cold exhaust at the outlet was set to $17.8^{\circ} \mathrm{C}$, and the airflow rate was $1423.7 \mathrm{~m}^{3} / \mathrm{h}$ per unit (air velocity: $3.26 \mathrm{~m} / \mathrm{s}$, blowing area: $0.121 \mathrm{~m}^{2}$ ), which was estimated based on measured values from a real machine (Appendix 1). Steady-state calculations were performed with a convergence criterion of less than $0.1 \%$ residual, and non-steady-state calculations were performed with a time interval of $30 \mathrm{~s}$.

Figure 10 depicts the simulated vertical cross-section of the air temperature distribution next to the cold exhaust outlets on the northern side of the building, with the three ASHPWH units in column \#1 operating concurrently. The temperature distribution shows that the cold exhaust sinks and remains near the ground. Much of the cold exhaust emitted from higher altitudes extends directly beyond the site boundary. Therefore, higher exhaust outlets are assumed to exert a smaller temperature effect at the measurement points within the boundary. Similarly, the low interference of the mesh fences on the east and west boundaries on outgoing airflow lead to different temperature effects between the cold exhaust from the outer (\#1 and \#4) and inner (\#2 and \#3) columns.

Table 4 Setup for simulation cases

\begin{tabular}{ll}
\hline Cases & Units in operation \\
\hline $\mathrm{T}$ & $\mathrm{T}-1, \mathrm{~T}-2, \mathrm{~T}-3, \mathrm{~T}-4$ \\
$\mathrm{M}$ & $\mathrm{M}-1, \mathrm{M}-2, \mathrm{M}-3, \mathrm{M}-4$ \\
$\mathrm{G}$ & $\mathrm{G}-1, \mathrm{G}-2, \mathrm{G}-3, \mathrm{G}-4$ \\
$\mathrm{I}$ & $\mathrm{T}-2, \mathrm{G}-2, \mathrm{M}-2, \mathrm{~T}-3, \mathrm{M}-3, \mathrm{G}-3$ \\
$\mathrm{O}$ & $\mathrm{T}-1, \mathrm{G}-1, \mathrm{M}-1, \mathrm{~T}-4, \mathrm{M}-4, \mathrm{G}-4$ \\
\hline
\end{tabular}


To compare the effect of the location of the exhaust outlets, five case simulations (Table 4) were performed by steady-state calculations. Cases T, M, and G are scenarios comparing the effect of exhaust height, with four units operating on the top, middle, and ground floors. Likewise, cases $\mathrm{I}$ and $\mathrm{O}$ are scenarios comparing the effect of the horizontal position, with six units operating in the inner (\#2 and \# 3 ) and outer (\#1 and \#4) columns. As temperature reference points, the values at spatial positions corresponding to the $\mathrm{N}-1, \mathrm{~N}-2$, and $\mathrm{N}-3$ measurement points (indicated in Fig. 1a) were used. For cases T, M, and G, the average values of deviation from the inflow temperature $\left(25.2^{\circ} \mathrm{C}\right)$ were $-0.83{ }^{\circ} \mathrm{C},-1.13{ }^{\circ} \mathrm{C}$, and $-2.57{ }^{\circ} \mathrm{C}$, respectively. For cases $\mathrm{I}$ and $\mathrm{O}$, the average deviation values were $-1.50{ }^{\circ} \mathrm{C}$ and $-1.37{ }^{\circ} \mathrm{C}$, respectively. The results show that under calm conditions, the cold exhaust from the middle and top floors registered $44 \%$ and $32 \%$ of the temperature effect of the ground floor, respectively; furthermore, the cold exhaust from the outer two columns registered $91 \%$ of the temperature effect of the inner two columns. The values obtained were used as the weighting factors in Eq. (2) for the effective amount of cold exhaust $H_{e}$.

The reproduction simulation was performed for the period from 4:00 to 5:00 a.m. on August 20, 2008, using non-steady state calculations. In the simulation, the ASHPWH units on the northern side were set in operation in accordance with the monitored state in the observation (Fig. 6b); that is, the

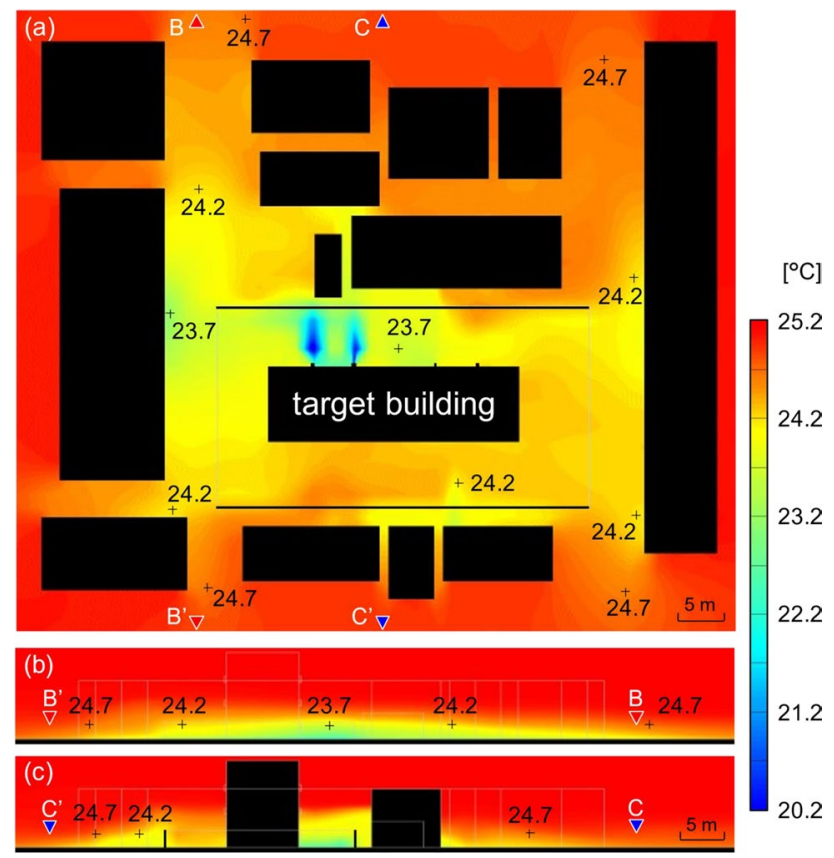

Fig. 11 Simulated distribution of air temperature at 5:00 a.m. on August 20, 2008: a horizontal distribution $1.5 \mathrm{~m}$ above the ground, b vertical cross-section along north-south line $\mathrm{BB}^{\prime}$, and $\mathbf{c}$ same as $\mathbf{b}$, but for line $\mathrm{CC}^{\prime}$ units are all off at 4:00 a.m. and initiate sequentially; thus, at 5:00 a.m., five units (G-1, M-2, G-2, M-3, and T-4) are in operation. Of the four units on the southern side that were not monitored in the observation, two (one on the top floor in the western column \#5 and one on the middle floor in the eastern column \#6) were assumed to be in operation from 4:00 to 5:00 a.m.

The simulation results at 5:00 a.m. are shown in Fig. 11. The areas around the building show a decrease in temperature, with changes of approximately -1 and $-0.5{ }^{\circ} \mathrm{C}$ on the northern side and the other three sides, respectively (Fig. 11a). The situation reproduced in the model roughly matches the results of the actual observations at 5:00 a.m. (Fig. 6). A more detailed examination reveals that the temperature effects at positions corresponding to the $\mathrm{N}-1, \mathrm{~N}-2$, and $\mathrm{N}-3$ measurement points are $-2.4,-1.4$, and $-1{ }^{\circ} \mathrm{C}$, respectively, with a large gradient in the east-west direction. This can be explained by the fact that the units on the ground floor, which have the largest temperature effect, operate only in the eastern two columns. However, this simulation result is not consistent with the observed results, where all measured values are almost uniformly within the range of -1.1 to $-1.0^{\circ} \mathrm{C}$. This discrepancy between the simulation and the observation suggests the influence of more complex local airflows that cannot be captured by the measurements in this study.

The simulation results (Fig. 11) show that the temperature near the outdoor units decreased non-uniformly due to the effect of cold exhaust. Equation (4) shows that in theory, the amount of cold exhaust $\left(H_{l}\right)$ of each unit decreases with the intake air temperature. However, as the intake air temperature of each unit was not measured, the rooftop air temperature $T_{a}$ was used as the air temperature in Eq. (4). This means that the decrease in the intake air temperature due to cold exhaust and its spatial non-uniformity was not considered in the calculation of $H_{l}$. This may cause uncertainty in the estimated values of the total amount of cold exhaust $\left(H_{n}\right)$ and the effective amount of cold exhaust $\left(H_{e}\right)$. As the simulated result is a reproduction of the scenario in which the largest temperature reduction occurred of all observed periods, it may be used to estimate the maximum range of errors attributable to this uncertainty. In the simulated result, the intake air temperature of the outdoor unit was $25.0{ }^{\circ} \mathrm{C}$ for $\mathrm{T}-4$ on the top floor, 24.9 and $24.7{ }^{\circ} \mathrm{C}$ for M-2 and M-3 on the middle floor, respectively, and $23.4^{\circ} \mathrm{C}$ for both G-1 and G-2 on the ground floor. Here, the average air temperature of the three grids on both sides and the top of each unit was used as the intake air temperature. Using the values in Eqs. (3) and (4), the $H_{1}$ was $-6.17 \mathrm{~kW}$ for T-4 on the top floor, -6.17 and $-6.16 \mathrm{~kW}$ for $\mathrm{M}-2$ and M-3 on the middle floor, respectively, and $-6.14 \mathrm{~kW}$ for both G-1 and G-2 on the ground floor; this yields a total of $-30.8 \mathrm{~kW}$. By using the inflow boundary temperature of $25.2^{\circ} \mathrm{C}$ in Eq. (1), 
$-30.9 \mathrm{~kW}$ was the total amount of cold exhaust $\left(H_{n}\right)$. This approximates to an overestimation of $0.33 \%$; thus, the difference is negligible. When the spatial non-uniformity of the intake air temperature was considered, the cold exhaust from the middle and top floors was $0.47 \%-0.56 \%$ larger than the ground floor. This proportion is negligible as it was smaller by two orders of magnitude than the weighting factors of $44 \%$ and $32 \%$ used to calculate the effective amount of cold exhaust $\left(H_{e}\right)$ in Eq. (2). Based on these results, consideration of the decrease in intake air temperature had no significant effect on the estimated $H_{n}$ or $H_{e}$.

Outside the site, the cooled region (where 1.5-m air temperatures were $0.5-1.5{ }^{\circ} \mathrm{C}$ lower than the inflow air) extends beyond the site boundary to the surrounding areas, forming a cool spot the size of a city block (Fig. 11a). Much of the cold exhaust from the ground floor, in particular, flows into the north-south street on the west side of the target building, where the 1 and $0.5^{\circ} \mathrm{C}$-cooled regions reach approximately 20 and $40 \mathrm{~m}$ downstream, respectively (Fig. 11b). The cold air accumulates in the space between the target building and another building located approximately $10 \mathrm{~m}$ to the north, and the altitude of the $1^{\circ} \mathrm{C}$-cooled region reaches more than $4 \mathrm{~m}$ above the ground (Fig. 11c).

Acknowledgements We would like to express our gratitude to everyone who has supported and offered us the opportunity to resume this research. This research was temporarily suspended due to the Great East Japan Earthquake that struck in 2011. We also thank those that helped reassemble the results that had almost been lost. Finally, our sincere gratitude to the anonymous reviewers for their constructive suggestions and insightful comments.

Author contribution K. Yamaguchi: conceptualization, methodology, validation, formal analysis, investigation, resources, data curation, writing — original draft, and visualization; T. Ihara and Y. Kikegawa: methodology, investigation, and resources.

\section{Declarations}

Ethics approval Not applicable.

Consent to participate Not applicable.

Consent for publication Not applicable.

Competing interests The authors declare no competing interests.

Open Access This article is licensed under a Creative Commons Attribution 4.0 International License, which permits use, sharing, adaptation, distribution and reproduction in any medium or format, as long as you give appropriate credit to the original author(s) and the source, provide a link to the Creative Commons licence, and indicate if changes were made. The images or other third party material in this article are included in the article's Creative Commons licence, unless indicated otherwise in a credit line to the material. If material is not included in the article's Creative Commons licence and your intended use is not permitted by statutory regulation or exceeds the permitted use, you will need to obtain permission directly from the copyright holder. To view a copy of this licence, visit http://creativecommons.org/licenses/by/4.0/.

\section{References}

Adelia AS, Yuan C, Liu L (2019) Shan RQ, Effects of urban morphology on anthropogenic heat dispersion in tropical high-density residential areas. Energ Buildings 186:368-383. https://doi.org/ 10.1016/j.enbuild.2019.01.026

Agency for Natural Resources and Energy (ANRE) (2019) Energy White Paper 2019. (In Japanese)

Alexander LV, Zhang X, Peterson TC, Caesar J, Gleason B, Klein Tank AMG, Haylock M, Collins D, Trewin B, Rahimzadeh F, Tagipour A, Rupa Kumar K, Revadekar J, Griffiths G, Vincent L, Stephenson DB, Burn J, Aguilar E, BrunetM TaylorM, New M, Zhai P, Rusticucci M, Vazquez-Aguirre JL (2006) Global observed changes in daily climate extremes of temperature and precipitation. J Geophys Res 111:D05109. https://doi.org/10. 1029/2005JD006290

Atwater MA (1972) Thermal effects of urbanization and industrialization in the boundary layer. Boundary-Layer Met 3:229-245. https://doi.org/10.1007/BF02033921

Bouchama A, Dehbi M, Mohamed G, Matthies F, Shoukri M, Menne B (2007) Prognostic factors in heat wave related deaths: A metaanalysis. Arch Intern Med 167:2170-2176. https://doi.org/10. 1001/archinte.167.20.ira70009

Bureau of Social Welfare and Public Health, Tokyo Metropolitan Government (2019) Situation of heat stroke deaths in summer of 2019 (Tokyo 23 wards). (in Japanese) https://www.fukushihoken.metro. tokyo.lg.jp/kansatsu/oshirase/R01-heatstroke.html

Cecchinato V, Corradi M, Fornasieri E, Zamboni L (2005) Carbon dioxide as refrigerant for tap water heat pumps: a comparison with the traditional solution. Int J Refriger 28(8):1250-1258. https:// doi.org/10.1016/j.ijrefrig.2005.05.019

Chen H, Ooka R, Huang H, Tsuchiya T (2009) Study on mitigation measures for outdoor thermal environment on present urban blocks in Tokyo using coupled simulation. Build Environ 44:2290-2299. https://doi.org/10.1016/j.buildenv.2009.03.012

Clarke JF (1972) Some effects of the urban structure on heat mortality. Environ Res 5:93-104. https://doi.org/10.1016/0013-9351(72) 90023-0

Davy R, Esau I, Chernokulsky A, Outten S, Zilitinkevich S (2016) Diurnal asymmetry to the observed global warming. Int J Climatol 37:70-93. https://doi.org/10.1002/joc.4688

Department for Business, Energy and Industrial Strategy (BEIS) (2019) Energy consumption in the UK (ECUK) 2019. https://www.gov. uk/government/statistics/energy-consumption-in-the-uk

Ecotope and NEEA (2015) Heat pump water heater model validation study, Report \#E15-306. https://ecotopewebstorage.s3.amazo naws.com/2015_001_1_HPWHModelVal.pdf

Energy Information Administration (EIA) (2018) 2015 Residential Energy Consumption Survey (RECS). https://www.eia.gov/consu mption/residential/data/2015

Enteria N, Awbi H, Santamouris M (2020) Perspective and advances of houses and buildings in hot and humid regions. In: Enteria N, Awbi H, Santamouris M (eds) Building in Hot and Humid Regions. Springer, Singapore. https://doi.org/10.1007/ 978-981-13-7519-4_1

Fan HL, Sailor DJ (2005) Modeling the impacts of anthropogenic heating on the urban climate of Philadelphia: a comparison of implementations in two PBL schemes. Atmos Environ 39(1):73-84. https://doi.org/10.1016/j.atmosenv.2004.09.031 
Guo JJ, Wu JY, Wang RZ, Li S (2011) Experimental research and operation optimization of an air-source heat pump water heater. Appl Energ 88:4128-4138. https://doi.org/10.1016/j.apenergy. 2011.04.012

Ichinose T, Shimodozono K, Hanaki K (1999) Impact of anthropogenic heat on urban climate in Tokyo. Atmos Environ 33(24-25):38973909. https://doi.org/10.1016/S1352-2310(99)00132-6

IEA (2018) The Future of Cooling, IEA, Paris. https://www.iea.org/ reports/the-future-of-cooling

Ihara T, Takane Y, Genchi Y (2015) Estimation of DALY loss due to heat stroke and sleep disturbance caused by air temperature rise in Tokyo, Japan. The 9th International Conference on Urban Climate (ICUC-9), Toulouse, France, 20-24 Jul 2015.

IPCC AR4 WG2 (2007) Parry ML, Canziani OF, Palutikof JP, van der Linden PJ, Hanson CE (ed.), Climate change 2007: impacts, adaptation and vulnerability, contribution of Working Group II to the Fourth Assessment Report of the Intergovernmental Panel on Climate Change, Cambridge University Press.

Japan Meteorological Agency (JMA) (2020) Climate Change Monitoring Report 2020. https://www.jma.go.jp/jma/en/NMHS/ indexe_ccmr.html

Johnson EP (2011) Air-source heat pump carbon footprints: HFC impacts and comparison to other heat sources. Energ Policy 39(3):1369-1381. https://doi.org/10.1016/j.enpol.2010.12.009

Karkour S, Ihara T, Kuwayama T, Yamaguchi K, Itsubo N (2021) Life cycle assessment of residential air conditioners considering the benefits of their use: a case study in Indonesia. Energies 14(2):447. https://doi.org/10.3390/en 14020447

Karl TR, Jones PD, Knight RW, Kukla G, Plummer N, Razuvaev V, Gallo KP, Lindseay J, Charlson RJ, Peterson TC (1993) A new perspective on recent global warming: asymmetric trends of daily maximum and minimum temperature. Bull Am Meteorol Soc 74:1007-1023. https://doi.org/10.1175/1520-0477(1993) 074\%3c1007:ANPORG\%3e2.0.CO;2

Kayaba M, Nakazawa K, Kondo M, ONO M, Minakuchi E, Sugimoto K, Honda Y, (2013) The nighttime usage of air conditioners among elderlies during summer. Jpn J Health Hum Ecol 79(2):47-53. https://doi.org/10.3861/jshhe.79.47

Kim D, Myeong S, Cha D, Kim Y (2019) Novel optimized operating strategies of two-phase injection heat pumps for achieving best performance with safe compression. Energy 187:115925. https://doi.org/10.1016/j.energy.2019.115925

Kimura F, Takahashi S (1991) The effects of land-use and anthropogenic heating on the surface temperature in the Tokyo Metropolitan area: a numerical experiment. Atmos Environ Part B Urban Atmos 25(2):155-164. https://doi.org/10.1016/09571272(91)90050-O

Kobayashi T (2018) 130 year history of building natural ventilation research in Jpn J Environ Eng. AIJ 751:749-759. https://doi.org/ 10.3130/aije.83.749(inJapanesewithEnglishabstract)

Kubota T, Chyee DTH, Ahmad S (2009) The effects of night ventilation technique on indoor thermal environment for residential buildings in hot-humid climate of Malaysia. Energy Build 41:829-839. https://doi.org/10.1016/j.enbuild.2009.03.008

Kubota T, Rijal HB, Takaguchi H (2018) Sustainable houses and living in the hot-humid climates of Asia Springer. Singapore. https://doi.org/10.1007/978-981-10-8465-2

Kusaka H, Kimura F (2004) Thermal effects of urban canyon structure on the nocturnal heat island: numerical experiment using a Mesoscale model coupled with an urban canopy model. J Appl Meteorology 43(12):1899-1910. https://doi.org/10.1175/jam21 69.1

Kuwayama T, Yamaguchi K, Okada K, Kikegawa Y, Kanda M, Varquez ACG, Darmanto NS, Darmanto PS, Ihara T (2019) Reduction effect of DALY of sleep disturbance and fatigue by air conditioner -Evaluation in Jakarta. Indonesia-, J LCA Jpn
15(1):2-9. https://doi.org/10.3370/lca.15.2(inJapanesewithE nglishabstract)

McGeehin MA, Mirabelli M (2001) The potential impacts of climate variability and change on temperature-related morbidity and mortality in the United States. Environ Health Perspect 109(Suppl 2):185-189. https://doi.org/10.1289/ehp.109-1240665

Michael A, Demosthenous D, Philokyprou M (2017) Natural ventilation for cooling in mediterranean climate : a case study in vernacular architecture of Cyprus. Energy Build 144:333-345. https:// doi.org/10.1016/j.enbuild.2017.03.040

Miyake Y, Aruga T, Inoue K, Okudera H, Kitahara T, Shimazaki S, Tsuruta R, Yokota H (2010) Characteristics of heatstroke patients in Japan; Heatstroke STUDY2008. Journal of Japanese Association for Acute Medicine 21(5):230-244. https://doi.org/10.3893/ jjaam.21.230(inJapanesewithEnglishabstract)

Morrison GL, Anderson T, Behnia M (2004) Seasonal performance rating of heat pump water heaters. Sol Energy 76:147-152. https:// doi.org/10.1016/j.solener.2003.08.007

Murage P, Hajat S, Kovats RS (2017) Effect of night-time temperatures on cause and age-specific mortality in London Environmental. Epidemiology 1(2):e005. https://doi.org/10.1097/ee9.0000000000 000005

Nastos PT, Matzarakis A (2008) Human-biometeorological effects on sleep disturbances in Athens, Greece: a preliminary evaluation. Indoor Built Environ 17(6):535-542. https://doi.org/10.1177/ 1420326X08097706

Narumi D, Ihara T, Fukuda S (2016) Study on the impact for sleep disturbance due to changing urban outdoor temperature. AIJ J Technol Des 22(52):1045-1048. https://doi.org/10.3130/aijt.22. 1045(inJapanesewithEnglishabstract)

Nekså P, Rekstad H, Zakeri GR, Schiefloe PA (1998) $\mathrm{CO}_{2}$-heat pump water heater: characteristics, system design and experimental results. Int J Refriger 21(3):172-179. https://doi.org/10.1016/ S0140-7007(98)00017-6

$\mathrm{Ng}$ E, Chen L, Wang Y, Yuan C (2012) A study on the cooling effects of greening in a high-density city: an experience from Hong Kong. Build Environ 47:256-271. https://doi.org/10.1016/j.buildenv. 2011.07.014

Obradovich N, Migliorini R, Mednick SC, Fowler JH (2017) Nighttime temperature and human sleep loss in a changing climate. Sci Adv 3(5):e1601555. https://doi.org/10.1126/sciadv.1601555

Ohashi Y, Genchi Y, Kondo H, Kikegawa Y, Yoshikado H, Hirano Y (2007) Influence of air-conditioning waste heat on air temperature in Tokyo during summer: numerical experiments using an urban canopy model coupled with a building energy model. J Appl Meteorol Climatol 46(1):66-81. https://doi.org/10.1175/ Jam2441.1

Ohashi Y, Ihara T, Yutaka Genchi Y (2014) Relationship between sleep disorder and nighttime outdoor thermal environment in the 23 wards of Tokyo. Papers on Environmental Information Science 28:367-372. https://doi.org/10.11492/ceispapers.ceis28.0_367 (in Japanese with English abstract)

Okamoto-Mizuno K, Tsuzuki K, Mizuno K, Iwaki T (2005a) Effects of partial humid heat exposure during different segments of sleep on human sleep stages and body temperature. Physiol Behav 83(5):759-765. https://doi.org/10.1016/j.physbeh.2004.09.009

Okamoto-Mizuno K, Tsuzuki K, Mizuno K (2005b) Effects of humid heat exposure in later sleep segments on sleep stages and body temperature in humans. Int J Biometeorol 49:232-237. https://doi. org/10.1007/s00484-004-0237-z

Oke TR (1982) The energetic basis of the urban heat island. Quar J R Met Soc 108:1-24. https://doi.org/10.1002/qj.49710845502

Oropeza-Perez I, Østergaard PA (2018) Active and passive cooling methods for dwellings: a review. Renew Sustain Energy Rev 82:531-544. https://doi.org/10.1016/j.rser.2017.09.059 
Rosenfeld AH, Akbari H, Bretz S, Fishman BL, Kurn DM, Sailor D, Taha H (1995) Mitigation of urban heat islands: materials, utility programs, updates. Energ Buildings 22:255-265. https://doi.org/ 10.1016/0378-7788(95)00927-P

Ryu Y-H, Baik JJ (2012) Quantitative analysis of factors contributing to urban heat island intensity. J Appl Meteorol Climatol 51(5):842854. https://doi.org/10.1175/JAMC-D-11-098.1

Santamouris M (2012) Cooling the cities - a review of reflective and green roof mitigation technologies to fight heat island and improve comfort in urban environments. Sol Energy 103:682-703. https:// doi.org/10.1016/j.solener.2012.07.003

Savio P, Cynthia R Solecki WD, Slosberg RB (2006) Mitigating New York City's heat island with urban forestry, living roofs, and light surfaces. New York City Regional Heat Island Initiative. The New York State Energy Research and Development Authority, Albany, NY.

Shapiro C, Puttagunta S (2016) Field performance of heat pump water heaters in the northeast, NREL, Golden, CO. https://www.nrel. gov/docs/fy 16osti/64904.pdf

Shibata Y, Tobita K, Matsubara N, Kurazumi Y (2010) Actual conditions of the recognition of heat disorders in the residential places and preventive measures for the elderly. Jpn J Biometeor 47(2):119-129. https://doi.org/10.11227/seikisho.47.119 (in Japanese with English abstract)

Singh H, Muetze A, Eames PC (2010) Factors influencing the uptake of heat pump technology by the UK domestic sector. Renew Energ 35:873-878. https://doi.org/10.1016/j.renene.2009.10.001

Suárez R, Escandón R, López-Pérez R, León-Rodríguez ÁL, Klein $\mathrm{T}$, Silvester S (2018) Impact of climate change: environmental assessment of passive solutions in a single family home in Southern Spain. Sustainability 10(8):2914. https://doi.org/10.3390/ su10082914

Synnefa A, Dandou A, Santamouris M, Tombrou M (2008) On the use of cool materials as a heat island mitigation strategy. J Appl Meteorol Clim 47, 2846-2856. https://www.jstor.org/stable/26172775

Takebayashi H, Kasahara M, Moriyama, M (2009) Study on mitigation of outdoor thermal environment by the unit of heat pump water supply. Transactions of the Society of Heating, Air-Conditioning and Sanitary Engineers of Japan 34(145):1-7. https://doi.org/10. 18948/shase.34.145_1 (in Japanese with English abstract)

Tamura H, Iwatsubo T, Hiraguchi H (2003) Numerical analysis of heat environment change in Tokyo 23 wards by hot-water heat pump system. Proc. 2003 Annual Conf. of The Society of Heating, AirConditioning and Sanitary Engineers of Japan, 721-724. https:// doi.org/10.18948/shasetaikai.2003.2.0_721 (in Japanese with English abstract)

Tanaka H, Umeda N (2015) Influence of the air current of air conditioner on physiological response and thermal comfort in elderly persons. Jpn J Biometeor 51(4):141-150. https://doi.org/10. 11227/seikisho.51.141

Tello-Oquendo FM, Navarro-Peris E, Gonzálvez-Maciá J (2019) Comparison of the performance of a vapor-injection scroll compressor and a two-stage scroll compressor working with high pressure ratios. Appl Therm Eng 160:114023. https://doi.org/10.1016/j. applthermaleng.2019.114023

Tuck NW, Zaki SA, Hagishima A, Rijal HB, Zakaria MA, Yakub F (2019) Effectiveness of free running passive cooling strategies for indoor thermal environments: example from a two-storey corner terrace house in Malaysia. Build Environ 160:106214. https://doi. org/10.1016/j.buildenv.2019.106214

van Loenhout JAF, le Grand A, Duijm F, Greven F, Vink NM, Hoek G, Zuurbier M (2016) The effect of high indoor temperatures on self-perceived health of elderly persons. Environ Res 146:27-34. https://doi.org/10.1016/j.envres.2015.12.012

Wei W, Ni L, Wang W, Yao Y (2020a) Experimental and theoretical investigation on defrosting characteristics of a multi-split air source heat pump with vapor injection. Energ Buildings 217:109938. https://doi.org/10.1016/j.enbuild.2020.109938

Wei W, Ni L, Zhou C, Wang W, Xu L, Yang Y, Yao Y (2020b) Technical, economic and environmental investigation on heating performance of quasi-two stage compression air source heat pump in severe cold region. Energ Buildings 223:110152. https://doi.org/ 10.1016/j.enbuild.2020.110152

Wilby RL (2003) Past and projected trends in London's urban heat island. Weather 58(7):251-260. https://doi.org/10.1256/wea.183. 02

Yamaguchi K, Ihara T, Kikegawa Y, Genchi Y, Endo Y (2009) Thermal environment and energy evaluation for heat island countermeasure in different residential areas. The 7th International Conference on Urban Climate (ICUC-7), Yokohama, Japan, 29 June-3 Jul 2019.

Yamaguchi K, Ihara T, Kikegawa Y, Genchi Y (2016) Evaluation for heat island mitigating potential of improving energy efficiency in urban areas - e-mobility and air source heat pump water heaters. In: Proceedings of the 23rd World Energy Congress 2016 Istanbul - Research Papers: Award Winner papers, 216-231.

Yang J, Liu H-Z, Ou C-Q, Lin G-Z, Zhou Q, Shen G-C, Chen P-Y, Guo Y (2013) Global climate change: impact of diurnal temperature range on mortality in Guangzhou. China Environ Pollut 175:131136. https://doi.org/10.1016/j.envpol.2012.12.021

Yokoyama R, Shimizu T, Ito K, Takemura K (2007) Influence of ambient temperatures on performance of a $\mathrm{CO}_{2}$ heat pump water heating system. Energy 32:388-398. https://doi.org/10.1016/j.energy. 2006.06.020

Yoshino H, Matsumoto HK, S, (2007) Passive cooling effect of traditional Japanese building's features. Manag Environ Qual 18(5):578-590. https://doi.org/10.1108/14777830710778337

Zhou Y, Shepherd JM (2010) Atlanta's urban heat island under extreme heat conditions and potential mitigation strategies. Nat Hazards 52:639-668. https://doi.org/10.1007/s11069-009-9406-z

Publisher's Note Springer Nature remains neutral with regard to jurisdictional claims in published maps and institutional affiliations. 